FERNANDO ALVES GOMES

\title{
Aplicações da Teoria Social Sistêmica no Desenho Normativo de Políticas Públicas: $O$ Caso do Sistema Nacional de Educação
}

\author{
Tese de Doutorado
}

Orientadora: Professora Associada Dra. Maria Paula Dallari Bucci

\author{
UNIVERSIDADE DE SÃO PAULO \\ FACULDADE DE DIREITO \\ São Paulo - SP \\ 2017
}


FERNANDO ALVES GOMES

\title{
Aplicações da Teoria Social Sistêmica no Desenho Normativo de Políticas Públicas: 0 Caso do Sistema Nacional de Educação
}

\begin{abstract}
Tese apresentada a Banca Examinadora do Programa de Pós-Graduação em Direito da Universidade de São Paulo, como exigência parcial para obtenção do título de Doutor em Direito, na área de concentração Direito do Estado, sob a orientação da Professora Associada Dra. Maria Paula Dallari Bucci.
\end{abstract}

UNIVERSIDADE DE SÃO PAULO

FACULDADE DE DIREITO

São Paulo - SP 


\section{AGRADECIMENTOS}

A Dona Lenir Alves, minha mãe, cuja dedicação amorosa e fiel jamais me abandonou um único momento, em nenhum aspecto, e que foi minha incentivadora e apoiadora desde a primeira hora, quando minha aspiração, que aqui está a se concretizar, não era mais que um desejo improvável. Jamais esquecerei o dia em que ela, durante um passeio pelo Largo de São Francisco, em sua primeira visita à cidade de São Paulo, ouvindo-me expressar minha vontade descrente de um dia atravessar as Arcadas como aluno, me disse com convicção: "Não duvide. É aí que você vai estudar. Eu tenho certeza, e você também deve ter". Essa tese, no que ela tiver de bom, é também sua, mãe, e o título, sendo meu, será também seu.

A Maria Paula Dallari Bucci, minha querida orientadora, que não apenas me deu um verdadeiro voto de confiança ao me aceitar como seu orientando, mas que também estendeu sua mão amiga e generosa quando eu mais precisei, reafirmando sua condição de verdadeira Doktormutter, expressão do jargão acadêmico alemão que traduz com precisão o que ela significa para mim. Sua grandeza intelectual, seu comprometimento com a ciência, sua orientação detalhista e rigorosa, e seu incentivo afetuoso estarão sempre comigo, onde eu estiver. Obrigado, Professora!

A Carolina Moreira Dourado Gomes, que entrou em minha vida sem aviso e nela se acomodou como se sempre tivesse estado ali, e que me colocou também na dela, quando eu já imaginava que não coubesse em nenhuma. Mais do que me mostrar o verdadeiro sentido de um matrimônio, ela inaugurou em mim um novo homem, com uma nova atitude e um novo coração. A cada dia, meu afeto por ti se acresce de uma nova razão e se confirma. Eu te amo com todas as forças de meu ser.

A Ricardo Silva Coutinho, meu amigo-irmão, que alentou meus dias em São Paulo com sua presença musical e criativa, e me acolheu no calor de sua família. Obrigado por tantas vezes me ajudar a clarear minhas ideias com suas observações e comentários sempre inteligentes e perspicazes, meu velho.

Nestas, eu agradeço à multidão de outras pessoas que eu não sou capaz de nominar aqui, mas que estiveram comigo durante essa minha travessia, e que por isso permanecerão em mim. 
A todos os professores, alunos $\mathrm{e}$ trabalhadores de escolas públicas do Brasil, com todo o meu apoio à sua luta, que é a minha luta. Avante! 


\section{RESUMO}

Fernando Alves Gomes. "Aplicações da Teoria Social Sistêmica no Desenho Normativo de Políticas Públicas: O Caso do Sistema Nacional de Educação". 246 p.. Doutorado. Faculdade de Direito, Universidade de São Paulo, São Paulo, janeiro de 2017.

A presente tese se propõe a atacar dois problemas jurídicos que se intersectam no campo das políticas públicas: o da insuficiência dos construtos teóricos usuais da ciência do direito para lidar com a complexidade causal e institucional de políticas, e o da renitente incapacidade dos projetos juridicamente estruturados para promover o direito à educação e alavancar a qualidade do sistema educacional no Brasil. O direito, sendo retardatário em sua participação na moderna investigação científica de políticas públicas, ficou durante décadas alheio ou deslocado em relação às áreas do conhecimento que têm explorado o tema. As principais elaborações da ciência do direito nesse território se apresentam, até hoje, sob a forma de "política do direito", "jurimetria", "legística", ou "legisprudência". Estes desenvolvimentos, no entanto, mantêm pouco ou nenhum diálogo interdisciplinar autêntico com o campo de investigação das políticas públicas, exibem excessivo aferro à dogmática, e tendem a fazer conexões diretas entre dados quantitativos e avaliações qualitativas, de modo que seus resultados práticos seguem, no mínimo, questionáveis. Por outro lado, novos esforços para a construção de uma teoria jurídica das políticas públicas têm gerado resultados mais animadores, ao contornar a rigidez típica da doutrina jurídica tradicional, requalificando suas conexões teóricas com outras ciências e estabelecendo importantes diretrizes metodológicas para a pesquisa futura. Este trabalho se reconhece como parte dessa segunda linhagem de estudos, e pretende contribuir para refinar a compreensão que o direito tem de seu papel nas políticas. A ideia aqui empreendida consiste em utilizar a estrutura cognitiva e conceitual, e o potencial heurístico da teoria dos sistemas (TS), para reinterpretar alguns dos problemas centrais da "policy analysis", e mediar a introdução de uma leitura jurídica no âmbito desta. Dessa forma, acreditamos poder demonstrar que o sistema social funcionalmente diferenciado da educação, no Brasil, tem sido "colonizado" por outros sistemas sociais, especialmente a política e a economia, por meio de instrumentos jurídicos. Assim, o sistema social da educação quedaria impedido de "imunizar" seus processos autorregulados de redução da improbabilidade da comunicação e de transformação de seres humanos em pessoas, fazendo-se necessária uma redefinição do papel das estruturas do Estado na governança da educação pública e das políticas correlatas.

Palavras-chave: políticas públicas; teoria de sistemas sociais; desenho institucional; direito constitucional à educação; sistema nacional de educação; educação pública. 


\begin{abstract}
Fernando Alves Gomes. "Applications of Social Systems Theory in the Legal Design of Public Policies: The Case of the National Education System". 246 pp. Doctorate. Faculty of Law, University of São Paulo, São Paulo, January 2017.

This dissertation addresses two legal problems that intersect in the field of public policies: that of the insufficiency of the usual theoretical constructs of the science of law to deal with the causal and institutional complexity of policies, and that of the persistent incapacity of legally structured projects to promote the right to education and to leverage the quality of the education system in Brazil. Law, lagging behind in its participation in the modern scientific investigation of public policies, has for decades been estranged or displaced in relation to this subject. The main strands of legal theorizing and practice in this field have been presented so far in the form of "politics of law", "jurimetrics", "legistics", or "legisprudence". These developments, however, maintain little or no authentic interdisciplinary dialogue with the field of public policy research, exhibit excessive clinging to legal doctrines, and tend to make direct connections between quantitative data and qualitative assessments, so that their practical results are, at least, questionable. On the other hand, new efforts to build a legal theory of public policies have generated more encouraging results, by circumventing the typical rigidity of traditional legal doctrine, requalifying its theoretical connections with other sciences and establishing important methodological guidelines for future research. We understand this work as part of this second line of studies, in that it aims to contribute to refine the understanding that legal scholars have of the role of law in public policies. The idea here is to use the cognitive and conceptual framework and the heuristic potential of systems theory (ST) to reinterpret some of the central problems of policy analysis and to mediate the introduction of a legal reading within it. In this way, we believe we can demonstrate that the socially differentiated social system of education in Brazil has been "colonized" by other social systems, especially politics and economics, with the use legal instruments. Thus, the social system of education would be prevented from "immunizing" its self-regulated processes for reducing the improbability of communication and for transforming human beings into persons, making it necessary to redefine the role of state institutions in the governance of public education and related policies.
\end{abstract}

Keywords: public policies; social systems theory; institutional design; constitutional right to education; national education system; public education. 


\section{ZUSAMMENFASSUNG}

Fernando Alves Gomes. "Anwendungen der Sozialsystemtheorie in der Rechtsgestaltung der öffentlichen Ordnung: Der Fall des nationalen Bildungssystems". 246 S. Doktorieren. Fakultät für Rechtswissenschaften, Universität São Paulo, São Paulo, Januar 2017.

Diese Dissertation befasst sich mit zwei rechtlichen Problemen, die sich im Bereich der öffenttlichen Ordnung überschneiden: die Unzulänglichkeit der üblichen theoretischen Konstrukte der Rechtswissenschaft, um mit der kausalen und institutionellen Komplexität der öffenttlichen Ordnung umzugehen, und die der anhaltenden Unfähigkeit rechtlich strukturierter Projekte das Recht auf Bildung zu fördern und die Qualität des Bildungssystems in Brasilien zu nutzen. Das Recht, das in seiner Teilnahme an der modernen wissenschaftlichen Untersuchung der öffentlichen Ordnung zurückbleibt, ist seit Jahrzehnten entfremdet oder vertrieben worden. Die Hauptstränge der legalen Theorie und Praxis in diesem Bereich wurden bisher in Form von "Rechtspolitik", "Jurimetrie", "Legistics" oder "Legisprudence" präsentiert. Diese Entwicklungen behaupten jedoch wenig oder gar keinen authentischen interdisziplinären Dialog mit dem Feld der öffentlichen Ordnung, zeigen übermäßiges Festhalten an Rechtsdoktrinen und neigen dazu, direkte Verbindungen zwischen quantitativen Daten und qualitativen Bewertungen herzustellen, so dass ihre praktischen Ergebnisse zumindest, fraglich. Auf der anderen Seite haben neue Bemühungen, eine rechtliche Theorie der öffentlichen Ordnung aufzubauen, mehr ermutigende Resultate hervorgebracht, indem sie die typische Starrheit der traditionellen Rechtslehre umgangen, ihre theoretischen Beziehungen zu anderen Wissenschaften vernachlässigt und wichtige methodische Richtlinien für die zukünftige Forschung festgelegt haben. Wir verstehen diese Arbeit als Teil dieser zweiten Reihe von Studien, indem sie dazu beitragen, das Verständnis, dass Rechtswissenschaftler haben die Rolle des Rechts in der öffentlichen Ordnung zu verfeinern. Dabei geht es darum, die kognitiven und konzeptuellen Rahmenbedingungen und das heuristische Potenzial der Systemtheorie (ST) zu nutzen, um einige zentrale Probleme der Politikanalyse neu zu interpretieren und die Einführung einer legalen Lektüre in ihr zu vermitteln. Auf diese Weise glauben wir, dass das sozial differenzierte soziale System der Bildung in Brasilien von anderen sozialen Systemen, insbesondere Politik und Wirtschaft, mit dem Einsatz von Rechtsinstrumenten "kolonisiert" worden ist. Das soziale System der Erziehung würde also daran gehindert werden, seine selbstregulierten Prozesse zu "immunisieren", um die Unwahrscheinlichkeit der Kommunikation zu reduzieren und Menschen in Personen umzuwandeln, was es notwendig macht, die Rolle staatlicher Institutionen in der Steuerung der öffentlichen Bildung und Bezogenen Politiken neu zu definieren.

Stichwort: öffentliche Ordnung; Theorie sozialer Systeme; institutionellen Design; Grundrecht auf Bildung; nationale Bildungssystem; öffentliche Bildung. 
Catalogação da Publicação

Serviço de Biblioteca e Documentação

Faculdade de Direito da Universidade de São Paulo

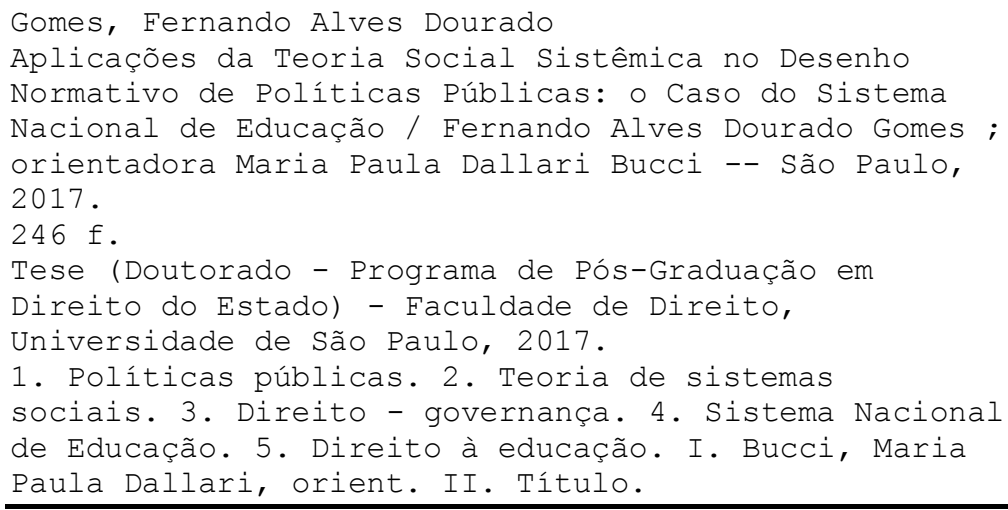




\section{SUMÁRIO}

1. INTRODUÇÃO: CONTEXTUALIZAÇÃO DO PROBLEMA, DELIMITAÇÃO DA TESE E DAS HIPÓTESES DE TRABALHO

1.1 O PROBLEMA

1.2 A PROPOSTA

1.3 A TESE E AS HIPÓTESES DE TRABALHO

2. CONCEITOS ESSENCIAIS DA TEORIA DE SISTEMAS SOCIAIS AUTOPOIÉTICOS APLICÁVEIS A UMA ANÁLISE JURÍDICA DO SISTEMA NACIONAL DE EDUCAÇÃO

2.1 EPISTEMOLOGIA CONSTRUTIVISTA E CAUSALIDADE NA TS

2.2 DIREITO COMO SISTEMA FUNCIONALMENTE DIFERENCIADO, ESTRUTURALMENTE ABERTO E OPERATIVAMENTE FECHADO

2.3 CODIFICAÇÃO E PROGRAMAÇÃO COMO ESTRUTURAS DO DIREITO 43

2.4 CONSTITUIÇÃO COMO ACOPLAMENTO ESTRUTURAL ENTRE DIREITO E POLÍTICA 48

2.5 SISTEMA EDUCACIONAL COMO SISTEMA SOCIAL FUNCIONALMENTE DIFERENCIADO. 53

2.6 ORGANIZAÇÕES COMO SISTEMAS SOCIAIS 62

3. A COMPLEXIDADE DAS POLÍTICAS PÚBLICAS: ESTADO, DIREITO, GOVERNANÇA E SISTEMAS

3.1 POLÍTICAS PÚBLICAS COMO CAMPO DE CONHECIMENTO TRANSDISCIPLINAR E COMPLEXO

3.2 PolíticAs PÚBLICAS E ESTADO

3.3 CONDUÇÃO DE POLÍTICAS PÚBLICAS: GOVERNANÇA COMO "STEERING"

3.4 DIREITO COMO ELEMENTO SISTÊMICO DE POLÍTICAS PÚBLICAS

3.5 UMA DEFINIÇÃO PARA O SISTEMA NACIONAL DE EDUCAÇÃO

4. INSTITUTIONAL ANALYSIS AND DEVELOPMENT FRAMEWORK (IAD) COMO INSTRUMENTO DE RECORTE DE UMA “ARENA DE AÇÃO" E SUA APLICAÇÃO AO SISTEMA NACIONAL DE EDUCAÇÃO.

4.1 UTILIDADE PRÁTICA DO IAD E COMPATIBILIDADE COM A TS

4.2 CONCEITO NORMATIVO DE INSTITUIÇÃO E ESTRUTURA DO IAD 
4.3 A ARENA DE AÇÃO: PERSPECTIVA SISTÊMICA E O CASO DO SNE

4.3.1 Elementos de uma arena de ação sob os postulados funcionais da TS

I. Atores/participantes.

II. Posições e ações admissíveis (ou competências decisórias).

III. Vínculos entre ações e resultados.

IV. Controle, custos e benefícios, e informação.

V. Qualidades dos atores/participantes.

4.3.2 Elementos estruturais básicos da organização do Sistema Nacional de Educação no Brasil, segundo o IAD

I. Operadores institucionais (atores/participantes)

II. Posições e "ações admissíveis" (competências decisórias)

4.4 CRITÉRIOS DE AVALIAÇÃO E QUALIDADE DA EDUCAÇÃO - ALGUMAS CONSIDERAÇÕES 148

5. SISTEMA NACIONAL DE EDUCAÇÃO COMO ARRANJO JURIDICAMENTE ESTRUTURADO DE GOVERNANÇA REFERIDO AO SISTEMA SOCIAL FUNCIONALMENTE DIFERENCIADO DA EDUCAÇÃO

5.1 Estruturas nORMativas do Sistema Nacional de Educação: Nível CONSTITUCIONAL.

5.1.1 Função constitucional e constitucionalização simbólica: codificação, tempo e mudança

I. Função constitucional: regulação da autopoiese dos sistemas jurídico e político e supraordenação do código lícito/ilícito.

II. Função constitucional, estabilidade temporal e mudança.

III. Limites materiais e o paradoxo das "cláusulas pétreas" no constitucionalismo moderno.

IV. A Constituição brasileira de 1988: resiliência ou constitucionalização simbólica?

5.1.2 Programação finalística e programação condicional na política constitucional de educação

I. Programação finalística, princípios jurídico-constitucionais e políticas públicas

II. Programação finalística e programação condicional no texto da Constituição brasileira de 1988

5.2 Estruturas normativas do Sistema Nacional de Educacional: Nível INFRACONSTITUCIONAL 
I. Características gerais, estrutura e divisão do conteúdo do PNE.

II. Conceito, classificação e estrutura das metas

5.2.2 Relações entre o PNE 14 e outras leis nacionais relevantes para a estrutura organizacional do SNE.

\section{CONCLUSÕES: APONTAMENTOS PARA UM FUTURO SISTEMA} NACIONAL DE EDUCAÇÃO

7. REFERÊNCIAS BIBLIOGRÁFICAS

8. ANEXO: ANÁLISE DESCRITIVA DAS METAS DO PNE 2014. 


\section{INTRODUÇÃO: CONTEXTUALIZAÇÃO DO PROBLEMA, DELIMITAÇÃO DA TESE E DAS HIPÓTESES DE TRABALHO}

\subsection{O PROBLEMA}

A falta de planejamento é muito comumente apontada como uma das principais mazelas do desenvolvimento social nas comunidades políticas, sejam pequenas vilas e cidades, sejam continentes inteiros. Podemos mesmo dizer que, em certo sentido, se tornou senso comum a crença de que, caso não se queira depender inteiramente da sorte, e receber de frente todo o impacto de intercorrências

futuras, previsíveis ou imprevisíveis, é preciso que alguma instância de ação pública, mormente o Estado, trate o planejamento com toda seriedade.

Por toda parte em que o poder político é invocado com o propósito de "conformar" o funcionamento de estruturas sociais ou "culturais" de forma planejada, instituições as mais diversas são colocadas sob a pressão de realizar propósitos expressos em comandos normativos. Estes comandos, além de expressarem finalidades a serem perseguidas, também estruturam, principalmente em contextos de primado das leis ("rule of law", Estado de direito), os principais processos 
decisórios por meio dos quais se tenta realizar alguma forma de direcionamento da atuação institucional - em termos tradicionais, alguma forma de orientação de meios para fins. Não se trata, portanto, de apenas estipular finalidades ou metas, e com isso de fixar uma "direção" a ser seguida, mas de criar condições para diminuir as discrepâncias entre as contingências de condições futuras e as expectativas de orientações presentes. O direito, nesse enredo, costuma ser apontado como uma via preferencial de obtenção de resultados planejados, e de exercício de controle sobre as estruturas sociais.

O planejamento puro e simples, como uma forma de lidar antecipadamente com possíveis problemas futuros, é antigo, como revela a história do planejamento urbano e das ações bélicas. Como objeto de um conhecimento específico referido à política, todavia, o planejamento só começa a experimentar avanços mais substanciais a partir dos anos 1950, com os trabalhos de Harold LASSWELL (1951), sobre a orientação de planos de ação política; de David EASTON (1953), sobre o sistema político e o estado de sua ciência; e de Charles LINDBLOM (1959), sobre os limites da racionalidade e da capacidade de planejamento. Desde então, a pesquisa e a literatura a ela conexa cresceram em volume, diversidade e especificidade, estendendo seu alcance para muitas outras esferas além do planejamento econômico, como que acompanhando a extensão das matérias sob a cobertura do welfare state. A própria ideia de planejamento passou por grandes transformações, até ser praticamente assimilada pelo conceito de governança ("governance", "steering") ${ }^{1}$.

Hoje, a ciência política, aliada a uma variedade de outras ciências, inclusive biológicas, matemáticas e da informação, oferece modelos explicativopreditivos e simulações computacionais elaboradas para uma variedade de situações

\footnotetext{
${ }^{1}$ A ideia de governança será o fio condutor de nossa reflexão, na medida em que o objetivo imediato do trabalho tem que ver com o uso do direito para induzir com sucesso o direcionamento de processos institucionais num determinado sentido. O conceito de governança que adotamos, como veremos mais à frente (cap. 3.3), possui um sentido específico, teórico-sistêmico, mas pode, sem problemas, acomodar uma definição como a proposta pelo TCU: "Governança no setor público compreende essencialmente os mecanismos de liderança, estratégia e controle postos em prática para avaliar, direcionar e monitorar a atuação da gestão, com vistas à condução de políticas públicas e à prestação de serviços de interesse da sociedade." (BRASIL, 2014b, p. 5)
} 
particulares (e.g., agent-based modelling, conceptual modelling, multi-agent policy simulations etc. ${ }^{2}$ ). Fornece também uma paleta sortida de teorias, com as quais pretende dar conta do que são e de como funcionam as políticas públicas - seus elementos, seus conceitos, as condições de sua transformação e manutenção, suas interconexões e intersecções causais com inúmeros fatores materiais e sociais, sua implementação, sua comunicação decisória etc. Apesar de toda essa movimentação, e apesar da importância atribuída às normas jurídicas em contextos de governança pública, a ciência do direito parece, no geral, se contentar com as próprias autoevidências, e tem participado muito menos da discussão central das políticas do que seria de esperar.

O direito, porém, não deixou de conceber formas próprias ${ }^{3}$ de autoorientação e autoaperfeiçoamento, em função da percepção dos resultados alcançados pelas leis, e de seu contraste com dados empíricos, científicos e estatísticos relevantes, tendo em vista finalidades juridicamente reconhecidas. Entre essas formas incluem-se as já antigas noções de política jurídica (REALE, [1940] 2000; Melo, 1994) e de jurimetria (LOEVINGER, 1949; 1962), bem como as concepções e aspirações da teoria da legislação (NOLL, 1973; KARPEN, 1986), também conhecida como legística (MORAND, 1999; FLÜCKIGER e GUY-ECABERT, 2008; KARPEN, 2009) ou legisprudência (MADER, 1986; 2006; WINTGENS, 2006; AlmeIDA, 2007).

Os esforços realizados nessas frentes apontam, em suma, para um propósito geral de entender como diferentes expressões normativas obtêm diferentes efeitos sociais, e como isso pode ser usado de maneira guiada, para transformar a realidade. $O$ desejo comum manifesto é "[estudar] não apenas a lei e suas possíveis interpretações, mas também as características concretas dos processos jurídicos de decisão" (NUNES, 2016, p. 16), para com isso "[reforçar] a faticidade (ou

${ }^{2} \mathrm{O}$ volume 21 da revista Artificial Intelligence and Law, de novembro de 2013, p. ex., é dedicado exclusivamente à questão da modelagem jurídica de políticas públicas através de instrumentos de tecnologia da informação e da computação, e traz um excelente apanhado das várias abordagens disponíveis. Cf. a propósito do uso de tecnologias da informação e da comunicação em governança, o manifesto da "ciência social computacional" em CONTE et al. (2012)

${ }^{3}$ Embora, como regra, enfaticamente apartadas da ciência do direito por um ambíguo "status próprio". 
realizabilidade) e a efetividade da legislação" e, ao mesmo tempo, "[otimizar o] círculo de comunicação legislativa e [promover a] melhoria da compreensão e do acesso aos textos legislativos" (MENEZES, 2007, p. 8), como forma de

"[atuar] no reordenamento do sistema jurídico em nome da manutenção da coerência (criação de barreiras às antinomias) e da consistência (densificação de comandos contidos em fontes legais por meio de atividade regulamentar para garantir a eficácia técnica), otimizando estratégias para o incremento do conhecimento real do Direito" (id. ibid., p. 9).

Contudo, os programas e a produção dessas disciplinas deixam transparecer certas características que, em nossa percepção, as impedem de extrair o máximo proveito do potencial de contribuição do direito para o debate científico transdisciplinar sobre institucionalização e governança de políticas públicas. Prevalecem, entre elas, uma obstinada vinculação a temas e termos estritamente jurídico-dogmáticos, bem como uma crença pouco realista na capacidade de influir planejadamente na realidade social por meio de mecanismos legais. Mais do que isso: faltam a essas disciplinas conexões conceituais e práticas mais diretas com o restante do campo de estudo das políticas, além de iniciativas inovadoras.

Com efeito, um olhar frio revela que tais estudos exibem uma visível falta de sintonia com o estado da arte da pesquisa social em políticas públicas, e tendem a enfatizar questões - como da estrutura normativa do processo legislativo, dos instrumentos de participação democrática na formação da lei, da "racionalização" e a simplificação legislativa, entre outras - que, embora nada desprezíveis, têm rendido pouco para o avanço da compreensão geral sobre a matéria (cf., p. ex., os resumos de FLÜCKIGER [2008, p. 23-24] e KARPEN [2009, p. 223]). É escasso o diálogo entre autores da legística (especialmente quanto à legística dita material) ou da jurimetria, e os proponentes das principais teorias e quadros conceituais de análise e desenvolvimento de políticas públicas (cf. SABATIER, 2007; CAIRNEY e HEIKKILA, 2014; HeIDEMANN e SALM, 2014). Também são poucas e limitadas as convergências acadêmicas acerca de que características formais, ou que modelos jurídicos de 
instituições políticas favorecem quais resultados efetivos. Evidentemente, está longe de satisfatória a conclusão de que

"a melhora da capacidade do direito de afetar a realidade social (legística material) envolve o desenvolvimento da avaliação legislativa, a introdução de corpos reguladores, a diminuição da burocracia, a introdução de expertise pluridisciplinar no processo de desenho legislativo, o planejamento e a coordenação da atividade legislativa, o uso de checklists e de guias de legística material e instrumentos analíticos (revisão do problema, definição de objetivos, escolha e avaliação de instrumentos), e o uso de novos tipos de normas, que sejam mais permeáveis ao progresso e a mudanças ambientais, sociais e econômicas (...). Esses processos podem ser codificados em guias de legística material. (FLÜCKIGER, 2010, p. 216 - trad.)

Muito embora essa "descolagem" do direito em relação à ciência política não seja necessariamente e per se negativa, o fato é que o tardio engajamento da teoria jurídica na compreensão científica da governança de políticas públicas recomenda, no mínimo por cautela, que seu acesso a este território se dê, em princípio, por meio de uma apropriação não dogmática da pesquisa já em curso fora do direito - e não como uma incursão direta das categorias de trabalho da doutrina sobre a matéria das políticas. Tal exigência requer do jurista disposição para manter um franco diálogo transdisciplinar, para abraçar novas distinções e formas de raciocínio, e, principalmente, para questionar e, eventualmente, deixar de lado ou relativizar as suas próprias.

Isso de modo algum obsta, antes estimula, que também a ciência jurídica ela mesma busque encarar diretamente as limitações com que se depara o campo de estudo das políticas hoje. Se o direito não pode simplesmente iniciar um novo debate sobre políticas e governança a partir de seus próprios critérios, não por isso deve se circunscrever a tão somente "tomar pé" do estado da investigação atual, em que pese sua notória defasagem. É importante que o direito se coloque propositivamente em relação aos grandes problemas da área, porém em bases distintas das de que vem costumeiramente se valendo. 
Por isso, o jurista pesquisador da governança de arranjos institucionais e políticas precisa levar em conta que muitas das teorias e das investigações aplicadas sobre os processos das políticas públicas ("policy process") não dão a atenção devida para problemas profundos das formas de construção da causalidade de que fazem uso, conscientemente ou não. Isso já foi acusado em diversos estudos sobre desenho de pesquisa e viés de recorte de caso na pesquisa empírica de ciências sociais (KING, KeOHANe e Verba, 1994; 2004; Collier e MahONeY, 1996; Braumoeller e Goertz, 2000; Brady e Collier, 2004; Mahoney e Goertz, 2006; GOERTZ e LEVY, 2007). É pouca, e recebe pouca atenção, sobretudo no domínio da pesquisa aplicada, a tematização dos vínculos entre cognição, construção social da causalidade e relações entre ciências "duras" e ciências sociais. Tudo se passa mais ou menos como se essas coisas se resolvessem por si mesmas.

Vários programas de investigação comuns da ciência política, portanto, consistem essencialmente em expor de maneira "objetiva" e organizada o uso das formas com que associam, p. ex., instrumentos, estratégias e processos factuais de decisão, a efeitos sobre as finalidades (auto)determinadas do sistema político, e se limitam a apontar o que entendem como relações de inferência entre fatores mensuráveis e efeitos qualitativos, entre variáveis dependentes e independentes. $\mathrm{O}$ que com isso fica de fora é justamente a questão de saber como se decide sobre quais formas explicam quais relações, ao mesmo tempo em que a causalidade mesma se transforma em uma questão "metodológica". Busca-se, antes de tudo, "descobrir" regularidades que possam ser usadas para estruturar análises e avaliações, prever trajetórias, e obter resultados práticos, ainda que predomine o casuísmo.

Consequentemente, boa parte do empenho por melhores modelos racionais de causação no campo das políticas, a despeito de avanços pontuais mais ou menos relevantes, tem produzido resultados ainda bastante irregulares, no geral de baixo potencial explicativo e de curto alcance. Sobre tal estado de coisas, SABATIER, citando Edella Schlager, comenta: 
"Com relação ao status das teorias positivas dos processos de políticas, eu concordo com a afirmação de Schlager (...) de que o campo das políticas públicas não é uma terra devastada, mas uma terra caracterizada por 'ilhas montanhosas de teoria, entremeadas, e às vezes ligadas, por colinas de métodos e conceitos compartilhados, bem como por trabalhos empíricos, sendo que tudo isso é cercado por oceanos de trabalhos descritivos que não estão ligados a nenhuma montanha teórica'." (SABATIER, 2007, p. 323 - trad.)

Noutra ponta dessa questão, a experiência com os projetos de desenvolvimento politicamente induzidos dos países periféricos, como exemplos concretos de planejamento, se provaram, ao longo dos anos, muito aquém de suas pretensões mais ambiciosas, e muitas vezes mesmo das modestas. Confrontada com os fatos, a quase euforia de um autor como MANHEIM (1972) diante das perspectivas da planificação é coisa que parece ter ficado irremediavelmente no passado. Planejar, como se imaginava possível, provou-se não ser. Não por acaso, há uma clara tendência dos administradores praticantes a olhar com certo desdém para as teorias; privilegia-se, na educação destes profissionais, o estudo de caso baseado em práticas recentes ou recorrentes, em detrimento das teorias do planejamento (WHITTEMORE, 2015). Essa observação, que é válida em relação à administração empresarial tanto quanto em relação às políticas públicas, também o é especificamente em relação ao direito, visto como parte estruturante da governança. Cada vez mais, muitas vezes inspirados em ideias (teóricas!) como a do "law and economics", estudiosos do direito se mostram vivamente interessados em encontrar e usar "o que funciona", com base em procedimentos estatísticos, medições e índices - muito embora ainda estejam longe de esclarecer suficientemente de que forma os instrumentos normativos jurídicos podem promover adaptações planejadas em outras estruturas sociais.

Nada obstante, a ciência política segue elaborando suas experiências, e apurando as descrições da complexidade que são e em que estão as políticas e a governança. Da mesma forma, novos esforços para a construção de uma teoria jurídica das políticas públicas continuam a surgir. Estes últimos, ao contornarem a 
rigidez típica da doutrina e do razoamento jurídico tradicional, e refinarem as conexões teóricas do direito com as outras ciências que se voltam para as políticas ${ }^{4}$, projetam prognósticos mais animadores e apontam um bom caminho para a pesquisa. Uma recensão muito instrutiva da literatura estadunidense sobre o estado da pesquisa na matéria, com uma útil discussão sobre a delimitação do campo de estudos em direito e políticas públicas, pode ser encontrada em KREIS e CHRISTENSEN (2013). Na Europa, representam a fronteira dessas iniciativas trabalhos como os de Renard, Caillosse e Béchillon (2000), Lascoumes e Les Galès (2004), VAN ASSCHE et al. (2015), e grandes projetos inter/transdisciplinares como o FuturICT (para um panorama completo, cf., http://futurict.inn.ac/; para sua iniciativa em governança e direito, cf. SMART et al. [2012]).

No Brasil, a obra pioneira de Buccl $(2006 ; 2008 ; 2013 ; 2016)$ tem feito avanços vigorosos em pelo menos duas direções fundamentais: ao estabelecer diferentes planos de realização da análise jurídica, em função do nível de "densidade" institucional em que têm curso os processos decisórios políticoadministrativos (níveis macro, meso e microinstitucional); e ao fixar premissas e diretrizes metodológicas básicas para o trabalho jurídico nessa área, reforçando a importância central de noções como complexidade, inter/transdisciplinaridade, diferenciação entre políticas e disposições jurídicas correlacionadas, entre outras ${ }^{5}$. Seu trabalho, assim, tem ajudado a pavimentar e também trilhado o caminho para uma discussão mais profícua entre estudiosos do direito e cientistas os mais diversos, não apenas sociais.

Porém, permanece aberta não só a tarefa de conectar o direito, eficazmente e na medida de sua real importância, ao estudo de ponta das políticas,

\footnotetext{
${ }^{4}$ E não apenas, ou precipuamente, com a estatística, como parece ser a tônica em certos círculos (cf. NUNES, 2016)

${ }^{5}$ Como premissas, Bucci indica: 1) a natureza institucional e complexa das políticas públicas; 2) a centralidade do conceito de decisão, especialmente o de decisão governamental; 3) a identificação das políticas públicas a ações racionais, estratégicas e em larga escala do poder público; 4) a irredutibilidade das políticas às disposições jurídicas que lhe forem correlatas; e 5) a dissociação entre as ideias de política pública e de política social. E como diretrizes metodológicas: 1) inexistência de um "direito das políticas públicas"; 2) inaplicabilidade da ideia de política pública como categoria jurídica; 3) necessidade de uma abordagem transdisciplinar; 4) fundamentação do trabalho na pesquisa empírica. Cf Buccl, 2008, p. 250-258.
} 
mas a própria construção de uma estrutura conceitual-teórica que permita lidar adequadamente com a complexidade da complexidade em políticas - e que, daí, permita elevar o patamar científico da governança. A partir daquelas posições de vanguarda apontadas, há ainda muito que avançar. Especialmente, na medida em que "[a] matriz conceitual do trabalho [da análise jurídica de políticas públicas] deve ser encontrada na Ciência Política" (Buccl, 2008, p. 250), torna-se imprescindível questionarmo-nos sobre as formas teóricas e práticas que essa "supracomunicação" realizada pela ciência política assume. É preciso pensar em como se pode constituir uma linguagem conceitual epistemologicamente unificada do conhecimento referido às políticas, e também em como obter modelos empíricos mais aptos a acomodar as especificidades do direito e de suas categorias.

\subsection{A PROPOSTA}

Diante desse cenário, gostaríamos de propor uma abordagem da governança jurídica, i.e., da governança juridicamente operada de instituições e políticas ("policies"), com base na teoria dos sistemas sociais autopoiéticos (TS), particularmente na versão elaborada por Niklas Luhmann. Nosso postulado central, portanto, será o de que a teoria que reúne as melhores condições epistemológicas para uma descrição científica da hipercomplexidade social e seus fenômenos, inclusive e particularmente do direito e das políticas públicas, e que é também a mais bem aparelhada para tratar o sistema jurídico em uma perspectiva multi ou transdisciplinar, é a TS. A justificativa desse ponto de vista será apresentada de forma estendida no cap. 2, junto com uma exposição de conceitos funcionaissistêmicos tidos como indispensáveis para o desenvolvimento posterior do argumento.

Contudo, três razões se destacam dentre as várias que qualificam a TS como um robusto paradigma teórico para a pesquisa em políticas públicas e seus desenhos jurídico-institucionais. Uma está ligada a como ela enfrenta e "resolve" ("assimetriza") o problema da autoimplicação do sujeito cognoscente na matéria de 
sua cognição, delimitando com isso um horizonte de possibilidades de construção da causalidade (tema a ser tratado no cap. 2.1).

Outra razão tem a ver com certa interpretação normativa da abordagem sistêmico-funcional de Luhmann. Como explica NEVES:

"Na sociedade mundial supercomplexa do presente, tornou-se uma exigência normativa que os códigos e programas de uma esfera de comunicação não se imponham, diretamente, a outra esfera de comunicação. Exige-se o respeito à autonomia de todo e qualquer discurso social. Por exemplo, é imperativo de justiça em uma sociedade complexa que 'o ponto central da racionalidade interna de um setor social autônomo, como pesquisa, saúde ou educação, não deve ser substituído pela racionalidade econômica'. Em geral, pode-se dizer que a racionalidade de um campo de comunicação não deve ser reduzida à de outro ou afirmar-se que os códigos e critérios de uma esfera social não devem ser sabotados pelas exigências de outra." (NEVES, 2004, p. 167-168).

Desse modo, ao caracterizarmos o sistema social funcionalmente diferenciado da educação (que será, como logo veremos, nosso "objeto" de observação empírica) como algo funcionalmente distinto da economia, da política, do direito e da organização burocrática estatal, estamos propondo que se pense em termos de como o direito pode orientar suas estruturas de modo a incentivar certa "imunização" do sistema educacional em relação à ação invasiva de outros sistemas de seu entorno - inclusive o do direito. Sem pretendermos adiantar a discussão, é bom deixar consignado que com o uso das expressões "imunização" ou "isolamento" não se quer dizer, de modo algum, que sistemas sociais são ou devem ser refratários a quaisquer conexões com seu ambiente, o que seria absurdo e inútil, mas sim que estas conexões se fazem dentro de um âmbito altamente restrito e seletivo de possibilidades, fora do qual o que se tem é uma situação de corrupção sistêmica. Isso nos obriga a pensar as especificidades da diferenciação funcional, e não a afirmar um isolamento genérico. Nesse sentido, parece-nos absolutamente consequente perguntarmo-nos de que forma podemos organizar nossos "contextos 
de ação" (LUHMANN, 1985, II, p. 175) de modo a tentar influir sobre certos efeitos correlatos. Este tópico será desenvolvido também no cap. 2.

Outra razão para a escolha da TS está ligada à forma como ela trata conceitualmente da complexidade social e das possibilidades de sua redução. A complexidade é um problema geral da governança de instituições em políticas públicas, e é também um ponto da construção teórica e prática que recebe bem menos atenção direta do que merece - no que a TS tem a vantagem de the dispensar especial importância. A noção de complexidade, com específica aplicação ao terreno das políticas e ao problema da governança como indução de resultados planejados, será objeto de reflexão aprofundada no cap. 3. Outros temas do cap. 3 serão a referência dessa "complexidade estruturada" ao Estado, seu significado para o direito como sistema social parcial, e a possibilidade de governança que se desenha a partir dessa conjuntura (com a ideia de "programas de redução de diferenças").

O emprego da TS como lente teórica, como é nossa convicção, será capaz de revelar problemas que quase sempre ou não são versados pela análise comum, ou o são apenas tangencialmente e de modo incompleto. Seus pressupostos epistemológicos (construtivismo, biologia da cognição, leis da forma); seus conceitos (acoplamento estrutural, complexidade, diferenciação funcional, equivalências funcionais, fórmula de contingência etc.); e suas distinções constitutivas (superteoria/diferença-guia, sistema/ambiente, distinção/observação, operação/estrutura, código/programa, autorreferência/hetero-referência, fechamento operativo/abertura estrutural, inclusão/exclusão etc.) nos permitem, por assim dizer, recriar as narrativas pelas quais se explicam (juridicamente inclusive) a permanência e a mudança nas políticas públicas, criando espaço para que as perguntas sejam recolocadas de maneiras novas, e que com isso surjam novas possibilidades de respostas. Em outras palavras, a TS é capaz de possibilitar o encaminhamento de observações e soluções diferentes das que ordinariamente se obteriam por meio de abordagens convencionais. 
A utilização da TS, sozinha ou em combinação com outras teorias, como paradigma para a orientação de estudos aplicados, tem se tornado mais comum recentemente $^{6}$. Longe de ser incompatível com abordagens práticas, ou de implicar um pessimismo niilista de pouca valia para estas, como sugere certa crítica comum, a TS pode ser muito útil para provocar e alimentar reflexões novas sobre como é possível promover realisticamente, por meios jurídicos, a governança de arranjos de instituições ${ }^{7}$ em uma política pública. Ainda que reconheçamos, como efetivamente faz Luhmann, que a abstração da teoria dos sistemas é "bastante infrutífera de um ponto de vista dedutivo, uma vez que implica um componente autorreferencial" (LUHMANN, 1986, p. 132), continua sendo possível sustentar a ideia de que a TS possui um elevado "valor heurístico, porque estimula e define a busca por outras possibilidades" (id., ibid.). Não se trata, com isso, de descartar os procedimentos científicos usuais como "errados", nem de sugerir que tudo seja feito de forma totalmente distinta, mas de problematizar e redefinir fundamentos teóricos elementares da pesquisa, de acordo com a visão da sociologia funcional-sistêmica.

Assim, embora nunca tenha buscado "aplicar" sua teoria, no sentido de nunca ter se mostrado interessado em promover análises empíricas de situações específicas, com vistas a "testar" suas hipóteses relativamente a certas variáveis, Luhmann tinha clareza acerca da capacidade da TS de se coligar a pesquisas aplicadas, bem como, de resto, a outras teorias. Como afirmou este autor,

"A teoria geral dos sistemas sociais se limita a converter as premissas usuais da pesquisa científica em funções. Ao fazê-lo, essa teoria parte de problemas muito abstratos. (...) Existe a possibilidade teórica de tentarmos entrelaçar estes problemas, elaborar uma interpretação cruzada de suas formulações, de modo a aumentar o poder racional de conceitos [da ciência "normal"] que isoladamente parecem ser bastante fracos. O objetivo final é submeter qualquer redução de complexidade a

${ }^{6}$ Contribuições semelhantes - propondo a incidência da ótica sistêmica sobre um conjunto heterogêneo de reflexões convergentes ou tangentes em políticas públicas e planejamento social podem ser encontradas em algumas frentes avançadas do trabalho em governança. BEUNEN, VAN ASSCHE e DUINEVELD $(2014,2015)$, p. ex., vêm trabalhando em um modelo de análise que combina teoria dos sistemas, IAD e outros modelos pós-estruturalistas, no que eles denominaram de "Evolutionary Governance Theory" (EGT).

${ }^{7}$ Voltaremos à ideia de "arranjo institucional” no Capítulo 2. A respeito, cf. Buccl, 2013. 
uma comparação sistemática com outras possibilidades funcionalmente equivalentes." (LUHMANN, 1986, p. 131-132 trad.)

"Poderia haver muitos projetos empíricos explorando a sensibilidade da autopoiese do sistema jurídico às mudanças sociais e políticas (ou os limites desta sensibilidade). Não há nenhuma incompatibilidade fundamental entre a teoria dos sistemas autorreferenciais e a pesquisa empírica, mas há uma tensão desconfortável entre as concepções teóricas e as possibilidades presentes da pesquisa empírica. Ao invés de rejeitar a teoria como não verificável, os críticos deveriam buscar ver as insuficiências de ambos os lados." (LUHMANN, 1992, p. 1439 - trad.)

O interesse em explorar pontos de contato e de tensão entre a TS e as pesquisas aplicadas em políticas públicas, pois, acaba por instigar também a busca por modelos de base empírica que se habilitem como bons candidatos à tarefa de dar "suporte" ao potencial heurístico da TS na análise jurídica de políticas públicas. Nesse particular, gostaríamos de avançar, subsidiariamente, a ideia de que o Institutional Analisys and Development Framework (IAD) oferece possivelmente as melhores ferramentas metodológicas disponíveis para o estudo de processos normativos de governança institucional em arranjos complexos. Isso não abole a possibilidade de eleger-se alguma teoria concorrente, ou uma combinação delas, como "ponte metodológica" entre o direito e o terreno da ciência política e suas adjuvantes, mas implica concordar com o que diz SABATIER, ao desenvolver a já citada metáfora de Schlager sobre o campo das políticas:

"A mais impressionante montanha [de produção teórica sobre policies] é, obviamente, a escolha racional institucional. (...) E dentro da tradição da escolha racional institucional, o mais impressionante corpo de trabalho relevante para o estudo de políticas públicas é o de Elinor Ostrom e seus colegas [IAD] (...)." (SABATIER, 2007, p. 324 - trad.) 
A particular utilidade do IAD para nosso propósito, sua compatibilidade com os pressupostos da TS, e sua leitura funcional serão discutidas e expostas no cap. 4.

A proposta prossegue, então, no cap. 5, com um sentido normativo e aplicado. Para fazermos uma demonstração de como a TS, valendo-se de recortes empíricos obtidos com a ajuda do quadro de análise proposto pelo IAD, pode ser útil para a reflexão sobre governança e desenho jurídico de políticas, utilizaremos seus recursos, exemplificativamente, no estudo do atual processo de construção da política nacional de educação, consubstanciada no Sistema Nacional de Educação.

A política nacional de educação brasileira nos fornece um problema real, renitente e grave, que, apesar do quanto já feito, precisa ser mais bem compreendido e orientado. A visão da TS pode ser bastante favorável a esse intento, na medida em que permita ressignificar concepções desbotadas ou diluídas (como as de "sistema educacional", "gestão democrática", "governança", "organização" etc.), e forçar o olhar para fora das molduras comuns de abordagens jurídicas centradas na lógica textual (redução de ambiguidades e de antinomias, reforço da coerência e da consistência semântica dos conceitos); nas qualidades técnico-dogmáticas das normas vigentes (transliteração de conceitos políticos em linguagem dogmática); ou na qualidade "científica" de abordagens quantitativas de fenômenos normativos e sociais ("direito e estatística").

A matriz jurídica da política de educação, no Brasil, tem bases constitucionais profundas, e está firmemente calcada na afirmação da educação como direito fundamental e como dever do Estado, relacionando-se, desde sua origem, a lutas históricas pelo planejamento, pela democratização e pela criação de um Sistema Nacional de Educação - cujo marco fundamental é o famoso Manifesto dos Pioneiros da Educação Nova (1932). As políticas de educação, a bem da verdade, podem ser consideradas nossos mais antigos esforços para elaborar e coordenar estruturadamente, ao longo do tempo e em nível nacional, ações a cargo 
do Estado, numa determinada matéria ${ }^{8}$. A gritante contradição entre estes fatos reconhecidos e os sérios problemas que ainda afetam o desenvolvimento da educação no país, especialmente no que tange sua qualidade e sua dispensação equitativa, chama imediatamente a atenção de qualquer analista interessado na questão educacional no país. Como se justifica essa incoerência, especialmente do ponto de vista jurídico?

Certo é que, já no Manifesto de 1932, denunciava-se a "falta de uma visão global do problema educativo", bem como a insistência em "reformas parciais, que se sucederam, na sua quase totalidade, na estreiteza crônica de tentativas empíricas". Já então também se deplorava o fato de que os esforços envidados na área "não lograram ainda criar um sistema de organização escolar, à altura das necessidades modernas e das necessidades do país" (BRASIL, 2010, p. 33-38). A história subsequente revelaria, em uma visão que parece prevalecer entre educadores e outros estudiosos da educação, uma série de "oportunidades perdidas" (SAVIANI, 2010, p. 392), numa tendência que apenas recentemente se reverteu, de forma ainda tímida e pouco firme (cf. resultados PNAD 2015).

Hoje, na continuação de uma já longa sequência de tentativas de reverter favoravelmente o quadro educacional brasileiro, encontra-se em plena vigência o mais recente Plano Nacional de Educação (Lei no 13.005, de 25 de junho de 2014 PNE 2014), que, em seu art. 13, determina:

Art. 13. O poder público deverá instituir, em lei específica, contados 2 (dois) anos da publicação desta Lei, o Sistema Nacional de Educação, responsável pela articulação entre os sistemas de ensino, em regime de colaboração, para efetivação das diretrizes, metas e estratégias do Plano Nacional de Educação.

Com um histórico apenas salpicado de avanços incrementais isolados, justifica-se pormos em dúvida nossa capacidade de fazer diferente dessa vez. O que

\footnotetext{
${ }^{8}$ Sobre a evolução geral do planejamento da educação no Brasil, cf. SILVA e SILVA, 2006; BORDIGNON, QUEIROZ e GOMES, 2011; KUENZER, CALAZANS e GARCIA, 2003; especificamente sobre a evolução do tratamento dispensado à educação nos textos constitucionais brasileiros, até o atual, cf. VIEIRA, 2007.
} 
poderia nos autorizar a dizer que agora não se tratará apenas de "apelar para o discurso edificante da cultura solidária" (ARROYO, 2013, p. 659)? O Sistema Nacional de Educação (SNE) será capaz de "sair do papel"? E, se sair, terá condições básicas de realizar aquilo a que se propõe? E mesmo que não nos bastem (como certamente não bastam) "leis melhores", o que pode significar isso, uma "lei melhor", de fato, para o caso?

As respostas para essas perguntas podem variar, mas dependem todas, para serem minimamente factíveis, da consideração de uma quantidade significativa de fatores heterogêneos, complexos e contingentes, cuja compreensão tende a ser incompleta. A disponibilidade de dados, estatísticas e estudos sobre a educação no Brasil, em seus diversos aspectos e sob diversos enfoques, é relativamente abundante, de modo que, nesse sentido, há material suficiente para alimentar as mais diversas análises. A abundância de dados sozinha, porém, desligada de uma estrutura teórico-conceitual que Ihe sirva de chave interpretativa, não é capaz de conduzir a uma melhor compreensão do assunto.

Quase tudo do que se escreveu acerca dos problemas que afetam o sistema educacional brasileiro aponta para alguns vilões reincidentes, que ameaçam também outras políticas relativas a direitos sociais: as desigualdades econômicas, como regra; o não cumprimento ou cumprimento deficiente da lei (ANTUNES, 2009); a ineficiência no emprego dos recursos públicos (DUARTE DA SILVA, 2013; NASCIMENTO et al., 2015); a relação descompassada entre federalismo fiscal e distribuição de competências em matéria educacional, entre outros problemas do federalismo (DINIZ, 2012; Costa, 2010; ABICALIL, 2013, 2014; DuARTE e SANTOS, 2014; SAVIANI, 2010; DOURADO, 2013); a fragilidade da fiscalização/controle da corrupção; a inconstância e inconsistência das políticas adotadas (SAVIANI, 2008), entre outros. Correspondentemente, as diferentes interpretações e soluções oferecidas tendem a se encaminhar pelo questionamento da "adequação" ou não das estruturas institucionais vigentes (normativas, políticas, administrativas) ao enfrentamento dessas pragas. 
Desse modo, prescrevem-se reformas constitucionais, regras de cooperação interfederativa, modelos de financiamento ou de suplementação financeira, orçamentos cogentes, regras de responsabilização, formas de organização administrativa, programas de crédito, de valorização profissional etc. mantendo-se, no mais, a esperança de que a educação venha a ser tratada com seriedade e prioridade. E tudo isso, sem dúvida nenhuma, de uma forma ou de outra, é necessário para que os problemas reais sejam enfrentados, embora, naturalmente, não seja o suficiente. Mas, se não se quiser tratar apenas da necessidade de (mais) reformas estruturais ou mais "clareza", nem de como obter sucesso na exortação da "boa vontade política", de que se tratará? O primeiro passo na direção de uma resposta talvez seja admitirmos que a visão empírica também precisa se questionar mais seriamente sobre as formas teóricas de que se vale para gerar as distinções e categorias básicas que ela mesma usa, a começar pela própria relação sujeito/objeto.

Em nossa visão, o interesse quase que invariavelmente voltado para a lógica das estruturas contingentes das leis e das instituições políticas concretas tem o poder de nos fazer "perder a floresta por causa das árvores" - ao menos tanto quanto a fixação no horizonte dos padrões estruturais da política e da normatividade vigentes pode nos impedir de observar outros aspectos da questão, potencialmente mais significativos, diante de problemas difíceis e muito persistentes. Em vista disso, nossa ideia é que a TS auxilie a mudar, momentaneamente ao menos, o foco de nosso questionamento: ao invés de indagarmos quais estruturas falharam/falham (e, a partir delas, quais podem vir a funcionar), e por que, procuraremos saber quais operações reforçam (ou enfraquecem) a identidade dos sistemas sociais enfocados (no caso, sobretudo, o jurídico e o educacional), e daí indicar onde as estruturas provavelmente deveriam mirar para tentar obter resultados diferentes.

\subsection{A TESE E AS HIPÓTESES DE TRABALHO}

A proposta acima delineada desemboca, então, na seguinte tese: 
A utilização da estrutura conceitual e do potencial heurístico da TS para orientar a aproximação entre direito e ciência política, em uma reflexão jurídica sobre a construção e a governança de arranjos institucionais, possibilita que se recriem as explicações usuais para o papel do direito na estabilidade e na transformação de políticas públicas, com novas premissas e novas perguntas - e, com elas, novas possibilidades de respostas. Com isso, teríamos possíveis melhores chances de instruir uma utilização adequada de ferramentas normativas para o fim de estimular transformações específicas em outros sistemas sociais - especialmente no sistema educacional, compreendido como sistema da sociedade (e não somente como administração estatal do aparato de meios postos à disposição do sistema educacional público).

Para sairmos do âmbito estritamente teórico, e testarmos não exatamente a validade, mas a viabilidade e a utilidade prática de uma leitura sistêmica das políticas públicas, usaremos os recursos desenvolvidos sob essa inspiração para avaliar o contexto normativo em que deverá se inserir, no Brasil, o arranjo institucional correspondente ao Sistema Nacional de Educação, que hoje se prepara como parte da implantação do atual Plano Nacional de Educação. A expectativa é apresentarmos um diagnóstico, bem como proposições para seu enfrentamento, diferentes dos costumeiramente encontrados na literatura sobre o assunto, mas que, ao mesmo tempo, integrem resultados alcançados pela pesquisa empírica usual.

Assim, como hipóteses de trabalho, acreditamos poder demonstrar, p. ex., (1) que há um viés em nossa estrutura jurídica que favorece uma "colonização" do sistema social funcionalmente diferenciado da educação pelos interesses autorreferidos de outros sistemas (econômico, político, moral, jurídico, burocrático); (2) que a fraca constitucionalidade geral ( $=0$ fraco acoplamento estrutural entre direito e política, ou constitucionalidade simbólica), associada ao largo predomínio de programas finalísticos na regulação infraconstitucional de direitos sociais, como a educação, tornam perigosamente frágil, mas igualmente indispensável, no caso brasileiro, a constitucionalização de políticas públicas; e (3) que, por isso, as melhores chances de refinamento do nosso arranjo institucional de governança da 
educação se localizam no nível infraconstitucional - haja vista a baixa probabilidade política e factual: (a) de que os sensíveis problemas da arquitetura do federalismo brasileiro sejam tratados, em conjunto ou em grandes blocos, por uma ampla reforma constitucional (e que essa, ainda por cima, seja capaz de estabelecer algum tipo de equilíbrio "Pareto-ótimo" em matéria fiscal); (b) de que as posições e as capacidades decisórias de operadores institucionais escolares, na estrutura organizacional do sistema de educação pública, sejam mais bem especificadas constitucionalmente (assumindo que essa constitucionalização possa ter efeitos concretos sobre os sistemas decisórios organizacionais reais); e (c) de que seja abandonada a prática reincidente de perpetuar disposições constitucionais transitórias, adiando indefinidamente o cumprimento de compromissos sobre direitos fundamentais - ou seja, negando-lhes vigência normativa.

Cabe enfatizarmos, para sermos mais precisos, que esse "olhar sistêmico" será apontado na direção denominada por Buccl (2013, p. 205) de "plano mesoinsitucional" da política pública. No plano mesoinstitucional de análise, exibe-se "o aspecto sistemático das políticas públicas, o nexo de unidade dos vários elementos que compõem o programa de ação governamental", pelo qual se definem os "papéis [dados] a cada um dos envolvidos na ação, constituindo posições subjetivas jurídicas, isto é, direitos e deveres estabilizados por força de normas e estruturas jurídicas" (id., ibid). Tal direcionamento é de fundamental importância para este estudo, já que nos permite ajustar o escopo da análise, isolando a faceta organizaciona ${ }^{\rho}$ da política de educação (ao lado da governamental, ou macroinstitucional, e da processual, ou microinstitucional - que também poderiam ser examinadas), em cujo perímetro se insere a ideia do Sistema Nacional de Educação. Essa "formação jurídica do arranjo institucional", como fator objetivo da organização dos meios colocados à disposição do Estado, tem um caráter estrutural de primeira magnitude, perfazendo "a ossatura e a musculatura" da ação do poder

9 Nesse particular, entendemos que, convertido em conceito funcional-sistêmico, o plano mesoinstitucional pode ser identificado ao nível das organizações, como sistemas de tomada de decisão, conforme o recorte proposto em LUHMANN, 1990c, p. 66 e ss. (cf. Fig. 1) 
público (Buccl, 2008, p. 265), e, por isso mesmo, reclama uma análise que ultrapasse a superfície de sua expressão formal, de sua "lógica normativa".

Cumpre também ressaltar que a tese defendida não implica nenhuma desconsideração em relação àquilo que política jurídica, jurimetria e legística (mormente a formal), entre outras protoformas de teorias jurídicas de políticas públicas, legaram de avanços para a busca de efetividade social do direito, mas tão somente que este legado precisa ser dimensionado com mais precisão, para que o direito possa ocupar um lugar ajustado no debate científico corrente. Nosso intento, antes de tudo, é "levar a sério" os supostos metodológicos adotados, e explorar o que nos parece ser uma boa intuição, com bons fundamentos.

Por fim, parece importante ainda darmos uma palavra sobre a distinção entre a proposta deste trabalho e a tarefa real de quem deve lidar com os processos políticos de formulação dos textos normativos. Há um aspecto da ação governamental que não pode ser reduzido a um tipo de "cálculo normativo", a inferências baseadas numa normatividade estrita - seja porque a própria lei deixa em aberto certas possibilidades, seja porque existam diversas formas de realização de uma possibilidade dada. Não se cuida de retomar a velha discussão sobre os limites (jurídicos) da discricionariedade das decisões dos agentes públicos, mas antes de considerar adequadamente que, dentre as normas e características sociais que afetam uma "situação de ação", encontram-se aquelas que determinam a "elaboração da agenda" e dos marcos normativos gerais de uma política, normalmente identificadas a um ciclo de mobilização, debates, estudos, negociações e votações (RIPLEY, 1995, p. 157 e ss.), cujos curso e resultado, embora influenciados, não podem ser controlados pelo direito.

Assim, o que há de ser de uma política qualquer depende sempre desse processo, cuja análise pertence mais propriamente ao campo da ciência política, e pode incluir avaliações sobre forma, sistema e regime de governo, sistema e dinâmica eleitoral e de voto, controle social e opinião pública, geopolítica, partidos políticos e estruturas de poder etc. O direito pode, sem dúvida, apontar caminhos para que se tire o máximo proveito de seus instrumentos, mas não pode, por isso, 
presumir que a política deva seguir sua orientação: até a baixa efetividade da lei pode ser ela mesma um movimento político mais ou menos intencional ou esperado. Isso ao menos no nível da formulação legislativa, onde o resultado produzido no campo da ciência torna-se apenas mais um argumento político, possivelmente forte, mas que pode ou não prevalecer, pode ou não ajustar-se à capacidade momentânea do sistema político. Com otimismo, podemos esperar que análises jurídicas dessa natureza sirvam para orientar, se não o processo decisório em si, quem sabe a avaliação jurídica das escolhas políticas e das práticas administrativas efetivamente realizadas. 


\section{CONCLUSÕES: APONTAMENTOS PARA UM FUTURO SISTEMA NACIONAL DE EDUCAÇÃO}

Em conexão com os mandamentos do PNE 14, e apesar de já vencido o prazo para edição da lei (art. 13), há, atualmente, dois projetos tramitando na Câmara dos Deputados, concernentes à criação de um Sistema Nacional de Educação.

Um é o Projeto de Lei Complementar n.․ 413, de 2014 (PLP 413/2014), de autoria do Deputado Ságuas Moraes (PT/MT), que, segundo sua ementa, "visa responder especificamente às disposições do artigo 23 da Constituição Federal, acelerada, agora, pela recente sanção da Lei no 13.005/2014 que estabelece o Plano Nacional de Educação, e dá outras providências." Seu alcance principal estaria "nas normas de cooperação federativa entre a União e os Estados, o Distrito Federal e os Municípios, e entre os Estados e os Municípios, para garantia dos meios de 
acesso à educação pública básica e superior regida pela Lei de Diretrizes e Bases da Educação Nacional” (PL 413/14, art. $1^{\circ}$ ).

O outro projeto é o Projeto de Lei n.ำ 5.519, de 2013 (PL 5519/2013), do Deputado Paulo Rubem Santiago (PDT/PE), atualmente apensado ao PL 2417/2011, o qual, por sua vez, está apensado ao PL 7420/2006. Seu objeto central é a instituição do Sistema Nacional de Educação como "articulação entre União, Estados, Municípios e Distrito Federal”, mas, por força dos apensamentos, inclui também disposições sobre qualidade da educação básica e responsabilização jurídica de "gestores públicos". Seu conteúdo, distribuído em seis artigos, tem um caráter quase que estritamente finalístico, cobrindo algumas poucas questões organizacionais muito amplas. Trata-se, basicamente, de uma declaração de intenções políticas, que avança sobre o terreno da qualidade por uma via burocrática e rígida, sem sensibilidade para com as delicadas especificidades dos processos educacionais, e que penaliza os sistemas fracos, determinando a suspensão de transferências entre entes quando do desatendimento de qualquer disposição sua (art. 5).

Apesar da existência de outros projetos, o PLP 413/2014 é hoje apresentado como a principal proposta em tramitação no Congresso, pelo próprio Ministério da Educação ${ }^{113}$. Independentemente disso, todos os projetos correntes, na leitura aqui proposta, evidenciam a distância entre as intenções declaradas e o uso das possibilidades práticas do direito, no tocante à instituição de um Sistema Nacional de Educação. Todos, apesar dos ares "progressistas" que se atribuem, tão somente reforçam a submissão dos processos educacionais e da organização escolar pública à burocracia técnica e politicamente enviesada de órgãos estatais, com a sobreposição de ditames normativos dominados pela lógica de outros sistemas sociais (político, econômico, religioso) às necessidades pedagógicas e organizacionais do sistema social funcionalmente diferenciado da educação.

Como buscamos demonstrar ao longo do desenvolvimento desta tese, a legislação ordinária incidente sobre a matéria educacional enfrenta grandes ${ }^{113} \mathrm{http}: / /$ pne.mec.gov.br/sistema-nacional-de-educacao 
dificuldades em deflagrar consequências estritamente jurídicas no campo do desenvolvimento qualitativo, sobretudo por ter que se orientar, aí, por uma programação predominantemente finalística, o que ocasiona um inevitável afrouxamento no código binário das operações jurídicas. Nesse sentido, a insistência em reformas baseadas no estabelecimento de metas e em mandamentos de cooperação implica a utilização da forma jurídica tão somente como instrumento simbólico da política. Não que metas sejam desnecessárias e apelos à cooperação sejam inúteis: eles apenas não se amoldam a uma forma juridicamente operável - ou se amoldam à custa da colonização da educação pelo direito, ou ainda da subversão do próprio sentido de cooperação. O mesmo raciocínio vale, por óbvio, para as tentativas de delimitação de um conceito jurídico de qualidade da educação.

De outra parte, a manutenção de uma estrutura organizacional do sistema público de ensino fortemente centrada na burocracia estatal e em concepções formais de democracia é responsável pelo deslocamento do eixo do sistema social da educação, das escolas e dos processos pedagógicos voltados para a formação de pessoas, para instâncias "técnicas" regidas por critérios "objetivos" de decisão, ou ainda para órgãos compostos por indicação política e altamente suscetíveis a influências de interesses incompatíveis com o desenvolvimento autônomo do sistema educacional público. Tal circunstância é ainda agravada pelo quadro de corrupção sistêmica que se verifica no direito brasileiro, que redunda não apenas em uma constitucionalidade simbólica, mas também em inúmeras disfuncionalidades institucionais, em diversos níveis.

Já a aplicação de programas condicionais, na forma da atribuição de consequências específicas ao descumprimento de deveres para com a educação (cf. cap. 4.4), apresenta riscos reconhecidos (XIMENES, 2012, p. 358), que facilmente ultrapassam quaisquer possíveis vantagens de seu emprego. Por isso, a ideia de que um aumento da responsabilização de administradores, gestores escolares e professores pelo não cumprimento de metas produziria maior adesão aos ditames legais é ilusória e mesmo perniciosa, como também é a ideia inversa e correlata da 
premiação e da bonificação, que atinge negativamente as ideias de igualdade e universalidade da educação (id., ibid.; BROOKE, 2006).

Outro aspecto da questão da atribuição de efeitos condicionantes está ligado ao sentido de uma possível "lei de responsabilidade educacional". Pela visão expressada no Documento SASE/MEC (Brasil, 2015), essa lei teria a função "definir claramente as responsabilidades, compartilhadas [entre os entes federados], sobre a oferta educacional e sobre sua qualidade", estabelecendo "normas de cooperação obrigatórias (sic) para dar sustentação à nova forma de organização da educação nacional", além de estipular "regras claras de supletividade vinculadas aos referenciais de qualidade, trazendo na sua base o princípio da interdependência e da cooperação". Para isso, seriam necessários "acordos em torno de regras federativas que possam constituir a base do sistema a ser organizado", as quais viabilizariam, entre outras coisas, "o funcionamento dos Conselhos de Educação e das instâncias de participação e pactuação, (...) dos espaços de gestão, de elaboração de normas, de controle social e de proposição de políticas públicas com ampla participação".

A contradição contida no ato falho da "cooperação obrigatória" nos parece, a esse respeito, muito reveladora. De fato, a única coisa que uma lei de cooperação definitivamente não pode fazer é tornar a cooperação obrigatória. A principal realização de uma lei dessa natureza, especialmente no campo da educação, em que o poder central detém enormes poderes, consistiria justamente em estabelecer normas que preservassem ao máximo a autonomia dos entes, induzindo sem constranger, ou constrangendo apenas sob condições bastante restritivas, mas sempre promovendo engajamento num determinado sentido sem impedir ações diversas. Como tudo que está ligado ao federalismo, tais normas de cooperação precisam lidar com uma unidade que é diversa de si mesma, com um todo que é, ao mesmo tempo, apenas parte - uma unidade problemática que é um dentre os entes federados autônomos, mas é também a própria representação do todo. Mais ou menos do mesmo modo que a Lei Complementar n.. 140/2011, uma lei de cooperação em matéria educacional poderia designar instrumentos para efetivação de parcerias, assinalando ações administrativas cabíveis a cada ente, bem como 
hipóteses de ação supletiva. Sem dúvida isso pode ser capaz de contribuir para que as relações interfederativas sejam pautadas por critérios mais claros, mas como e o quanto o desenvolvimento qualitativo da educação pode se beneficiar disso é algo que hoje só se pode conjecturar.

Assim, voltamos às nossas hipóteses de trabalho para, em vista de todos os argumentos aduzidos no desenvolvimento desta tese, confrontá-las e, de forma sintética, confirmá-las ou refutá-las.

(1) Quanto à ideia de que há um viés em nossa estrutura jurídica que favorece a colonização do sistema social funcionalmente diferenciado da educação pelos interesses autorreferidos de outros sistemas (econômico, político, moral, jurídico, burocrático), não nos parece haver dúvidas de ser este precisamente o caso: a distribuição federal de competências, o papel institucional atribuído ao Estado, a composição e as competências decisórias de Conselhos e Fóruns, a posição das escolas frente à estrutura burocrática - tudo isso reforça essa percepção, cujo lastro é a visão funcional sistêmica da educação.

(2) Quanto à debilidade geral da constitucionalidade, ou constitucionalização simbólica, no Brasil, igualmente não nos parece haver dúvidas de que seja o caso - independentemente de interpretações alternativas, o diagnóstico final parece-nos inevitável. O predomínio de programas finalísticos na regulação constitucional do direito à educação, porém, não pode ser apontado como fator causal significativo para a conformação deste quadro, haja vista que não apenas o comum na regulação constitucional de políticas é que assim seja, mas também que os dispositivos constitucionais programados de modo condicional surtem efeitos praticamente irrelevantes (CF, art. 34, VII, 'e'; art. 35, III; art. 208, § $2^{\circ}$; ADCT, art. 60, XI). No fim das contas, a constitucionalização de políticas públicas é, sim, importante, no sentido de que estimula a manutenção de políticas de Estado, retirando a matéria, ao menos em parte, das flutuações políticas ordinárias das democracias representativas.

(3) Já no nível da regulação infraconstitucional da educação, a forte prevalência de programas finalísticos se mostra importante para certa orientação das 
ações do Estado, no que permite, ao menos em tese, avaliar a maior ou menor consonância entre o que é determinado que se faça, o que é efetivamente feito, os resultados pretendidos e os resultados alcançados - mas sem que disso se possam extrair consequências propriamente jurídicas, previsíveis, acionáveis e exigíveis. Isso para não falarmos da duvidosa utilidade do recurso à intervenção judicial, no que diz respeito a uma melhor orientação de políticas públicas, as de educação em particular. De outra parte, a grande concentração de poderes na esfera federal, associada ao domínio da burocracia sobre os processos pedagógicos da educação pública, esvazia quase por completo o sentido da gestão democrática da educação e alija seus principais operadores - escolas e profissionais da educação - de posições com qualquer tipo de capacidade decisória relevante.

(4) Quanto à ideia de que o aperfeiçoamento qualitativo do arranjo institucional de governança da educação pública brasileira depende mais da conformação de normas infraconstitucionais do que de reformas constitucionais, é preciso admitir que a realidade é bem mais complexa. Intervenções no nível constitucional federal não são simplesmente dispensáveis. Como vimos (cap. 4.4), o aumento do investimento público em educação experimentado nos últimos anos se deve fundamentalmente às reformas constitucionais que criaram primeiro 0 FUNDEF, e depois o FUNDEB. Igualmente, a determinação, por norma constitucional, de que se fixassem em lei planos de carreira e piso salarial nacional para os "profissionais da educação escolar pública" (CF, art. 206, V e VIII, com redação dada pela EC n. ${ }^{\circ}$ 53/2006) deve ser considerada um passo importante para a elevação dos patamares qualitativos da educação. Portanto, mudanças constitucionais, sim, importam.

Por outro lado, devemos considerar que o FUNDEB, por estar inserido no $A D C T$, tem prazo de validade previamente estabelecido, de modo que sua renovação depende de circunstâncias políticas futuras sobre as quais não se pode ter nenhuma garantia. Ademais, embora essencial para o avanço de políticas educacionais mais sólidas, o aumento de investimentos por si só não induz ao desenvolvimento qualitativo: demonstram-no os muitos casos, alguns inclusive 
dentro da própria América do Sul, de países com investimento por aluno menor que o do Brasil, mas com melhor desempenho educacional (PISA 2015). Quanto ao piso salarial, a proposição da ADI 4167, questionando a constitucionalidade da lei que regulamentou a matéria (Lei Federal 11.738/2008), assim como o pedido de modulação dos efeitos da decisão que a julgou improcedente, e a não atribuição de efeito vinculante no que toca à questão da jornada de trabalho (parágrafo $4^{\circ}$ do artigo $2^{\circ}$ da referida Lei) são indicativos das dificuldades que se antepõem à efetivação de seus efeitos práticos.

Pela via infraconstitucional, poder-se-ia, em primeiro plano, operar sobre a configuração organizacional do sistema de governança da educação (sobretudo o $\mathrm{SNE}$, mas também os sistemas parciais dos Estados), de modo a tentar contornar as dificuldades já indicadas para a efetivação de reformas constitucionais (baixa probabilidade política e factual de uma ampla e satisfatória reforma do federalismo brasileiro, e da institucionalização de uma verdadeira autonomia escolar). Isso se faria com uma lei que conferisse maior peso e maiores competências às posições ocupadas pelos atores do sistema social da educação, tornando preponderantes, nos processos decisórios relativos a distribuição de recursos, definição de investimentos, e organização e funcionamento escolar, as razões e necessidades pedagógicas e profissionais percebidas e elaboradas no âmbito do próprio sistema social da educação. Trata-se de uma percepção que se coaduna com algumas das características mais marcantes de sistemas educacionais altamente desenvolvidos: valorização profissional e independência pedagógica de professores, e autonomia escolar para a determinação de suas próprias prioridades, dentro do universo curricular disponível (EURYDICE EUROPEAN UNIT, 2007; WOESSMAN et al, 2008; LAVRIJSEN e NICAISE, 2012; OCDE, 2013; SUGGET, 2015)

Com efeito, chama atenção o fato de que não há atribuição constitucional de um papel próprio e destacado às escolas nas instâncias de governança do sistema educacional, na condição de base, por excelência, dos processos educativos, com o consequente peso institucional traduzido em competências decisórias e proteções legais. A conformação jurídico-institucional dos operadores do 
sistema de administração educacional, no nível constitucional, reconhece, basicamente, as pessoas jurídicas de direito público interno identificadas aos três níveis da federação, e sugere, pela autonomia conferida às universidades públicas (CF, art. 207), a relevância política destas, o que the confere uma clara vantagem. Como são baixas as chances de que haja o reconhecimento de tal status para as escolas nesse nível (para não falarmos na possibilidade de que ele assumisse um caráter meramente nominal), sua inclusão entre os protagonistas institucionais do sistema dependeria, na melhor das perspectivas, do desdobramento normativo da "gestão democrática" (CF, art. 206, VI) num nível intermediário de regras ("regras de escolha coletiva", ou infraconstitucionais).

Ressalte-se, porém, que as regras de competência legislativa e material podem constituir, e certamente constituem, em virtude de seus postulados intrínsecos concernentes à separação de poderes e à autonomia federativa, razões juridicamente oponíveis aos avanços da influência dos operadores escolares, ou com "composição democrática" (especialmente Fóruns de Educação) sobre a arena normativa e administrativa. Normas de cooperação, nesse sentido, poderiam talvez ser úteis para amenizar os efeitos desse "descolamento" entre o modus operandi da política e as necessidades do sistema educacional, por meio de estímulos (que não envolvessem recompensas diretas, como o aumento na destinação de recursos) a que os Estados promovessem, conjuntamente, a autonomia e a prestação de contas ("accountability") não punitiva das escolas e de seus profissionais. No fundo, trata-se não só de aprofundar, mas de qualificar a gestão democrática da educação pelo desenvolvimento de uma percepção mais refinada das especificidades desse sistema social. Certamente não seria o bastante, especialmente se considerarmos apenas o que os mecanismos jurídicos podem efetivamente fazer, mas sem dúvida seria um grande avanço.

No fim das contas, a influência das mudanças legislativas sobre a evolução qualitativa da educação continuaria a depender da consistência, ao longo do tempo, de seu direcionamento no sentido de aumentar a "imunidade" do sistema social da educação, ou seja, de fortalecer, nos processos decisórios relacionados, a 
lógica do sistema educacional, restringindo as possibilidades de intervenção de outras "lógicas" - ou seja, da ação intrusiva e potencialmente corruptora dos códigos de outros sistemas sociais funcionalmente diferenciados. Rigor educacional, ênfase em competências sociais, atenção às necessidades individuais dos alunos, profundidade, riqueza e liberdade pedagógica, como condições do desenvolvimento qualitativo da educação, são frutos do próprio sistema educacional, radicadas em uma formação exigente e altamente qualificada de professores motivados e respeitados. E é um sentido em que se pode compreender a autopoiese do sistema educacional.

De resto, no plano jurídico, é preciso considerar também o peso do entendimento constitucional sobre regras como a da laicidade do Estado e da gratuidade do ensino público, e de princípios como os da "liberdade de aprender, ensinar, pesquisar e divulgar o pensamento, a arte e o saber", e do "pluralismo de ideias e de concepções pedagógicas". A maior ou menor adstringência da legislação referida a estas normas, e/ou da interpretação constitucional que se fizer sobre elas, pode ter efeitos benéficos ou muito perniciosos para um sistema educacional que se quer movido essencialmente por valores pedagógicos (e não de mercado, ou religiosos, ou burocráticos, ou ainda de ideologias nacionais).

Utilizar o direito como um programa de redução de diferenças, quer dizer, como um meio de promoção de "ajustes" no funcionamento de outros sistemas sociais funcionalmente diferenciados requer um tipo de ação indireta, um tipo de autoinfluência heterodeterminada, uma disposição das estruturas internas do direito voltada, reflexivamente, para as possíveis reações de outros sistemas, que se valem de suas próprias observações e descrições para reagir do seu específico modo e nas suas próprias operações a estímulos do ambiente. Insistir em estratégias baseadas em mais "precisão", em mais "clareza", em mais "responsabilização", enfim, na suposição de que o sentido das palavras empregadas para estruturar a lei estabelece uma equivalência semântica entre sistemas distintos, e de que a obtenção dos efeitos desejados depende da "força" do direito, como se com assim se pudesse garantir uma espécie de comunicação cibernética intersistêmica, parece- 
nos a própria negação da complexidade e da delicadeza de relações que, apesar de altamente improváveis, existem e funcionam. 


\section{REFERÊNCIAS BIBLIOGRÁFICAS}

ABICALIL, Carlos Augusto. Federalismo Brasileiro e Cooperação Interfederativa em Educação: Entre as Autonomias e Equidade, in Roteiro, v. 39, n.ำ 1, p. 11-38, 2014.

ABICALIL, Carlos Augusto. Sistema Nacional de Educação: os Arranjos na Cooperação, Parceria e Cobiça sobre o Fundo Público na Educação Básica, in Educação e Sociedade, v. 34, n.ำ124, p. 803-828, 2013.

ADRIÃO, T.; GARCIA, T.; BORGHI, R. F.; BERTAGNA, R. H.; PAIVA, G.; XIMENES, S. Sistemas de Ensino Privados na Educação Pública Brasileira: Consequências da Mercantilização para o Direito à Educação, relatório de pesquisa disponível em http://flacso.org.br/?publication=sistemas-de-ensino-privados-na-educacao-publicabrasileira-consequencias-da-mercantilizacao-para-o-direito-a-educacao, acesso em junho de 2016.

ALMEIDA, Marta Tavares de. A Contribuição da Legística para uma Política de Legislação: Concepções, Métodos e Técnicas, in Congresso Internacional de Legística: Qualidade da Lei e Desenvolvimento, 2007, Belo Horizonte: Assembleia Legislativa do Estado de Minas Gerais, p. 83-102. Disponível em: <http://www.almg.gov.br/publicacoes/legistica/legistica_marta.pdf>.

ANDERIES, John M., e JANSSEN, Marco A. Robustness of Social-Ecological Systems: Implications for Public Policy, in Policy Studies Journal, v.41, n.ํ 3, p. 51437, 2013.

ANDERSON, Philip. Complexity Theory and Organization Science, in Organization Science v. 10, n. $^{\circ} 3$, ed. especial "Application of Complexity Theory to Organization Science", p. 216-232, 1999.

ANDREWS et al. OECD and PISA Tests are Damging Education Worldwide, in The Guardian, edição de 06 de maio de 2014, disponível em https://www.theguardian.com/education/2014/may/06/oecd-pisa-tests-damagingeducation-academics

ANTUNES, José Luiz Cordeiro. Impasses e Políticas Atuais em Relação à Educação, in VALLE, Bertha B. R. (coord.), Políticas Públicas de Educação. Curitiba: IESDE Brasil, 2009, p. 127-144.

ARANTES, Rogério B., e COUTO, Cláudio G. Construção Democrática e Modelos de Constituição, in DADOS - Revista de Ciências Sociais, v. 53, n.ำ 3, p. 545-585, 2010.

ARAÚJO, Gilda Cardoso de. Constituição, Federação e Propostas para o Novo Plano Nacional de Educação: Análise das Propostas de Organização Nacional da Educação Brasileira a Partir do Regime de Colaboração, in Educação e Sociedade, vol. 31, n.ำ112, 2010.

ARROYO, Miguel G. Reinventar a Política - Reinventar o Sistema de Educação, in Educação e Sociedade, v. 34, n.ำ 124, p. 653-678, 2013. 
ATIYAH, Patrick S. e SUMMERS, Robert S. Form and Substance in Anglo-American Law - A Comparative Study of Legal Reasoning, Legal Theory, and Legal Institutions. Oxford: Claredon Press, $3^{\mathrm{a}}$ reimpressão, 1996.

AZEVEDO, Janete M. L. Reflexões sobre políticas públicas e o PNE. In: Retratos da Escola, v. 04, 2010.

BACCARO, Lucio, e PAPADAKIS, Konstantinos. The Downside of ParticipatoryDeliberative Public Administration, in Socio-Economic Review, v. 7, p. 245-276, 2009.

BAER, Werner. The Brazilian Economy: Growth and Development. Boulder: Lynne Rienner, 2008.

BALKE, Tina; DE VOS, Marina; e PADGET, Julian. I-ABM: combining institutional frameworks and agent based modeling for the design of enforcement policies. In: Artificial Intelligence and Law, vol. 21, p. 371-398, 2013.

BARALOU, Evangelia; WOLF, Patricia, e MEISSNER, Jens O. Bright, Excellent, Ignored: The Contribution of Luhmann's System Theory and it's Problem of NonConnectivity to Academic Management Research, in Historical Social Research, v. 37, n. $=$ 4, p. 289-308, 2012.

BARNETT, Larry D. Legal Construct, Social Concept. A Macrosociological Perspective on Law. New Brunswick e Londres: Aldine Transaction, 2010.

BERTALANFFY, Ludwig von. Teoria Geral dos Sistemas: Fundamentos, Desenvolvimento e Aplicações. Petrópolis: Editora Vozes, 7ª̣ Ed., 2006.

BEUNEN, Raoul; VAN ASSCHE, Kristof; e DUINEVELD, Martjin. Evolutionary Governance Theory. An Introduction. Heidelberg/New York/Dordrecht/London: Springer International Publishing, 2014.

BEUNEN, Raoul; VAN ASSCHE, Kristof; e DUINEVELD, Martjin. Evolutionary Governance Theory. Theory and Applications. Heidelberg/New York/Dordrecht/London: Springer International Publishing, 2015.

BLOMQUIST, William e DeLEON, Peter. The Design and Promise of the Institutional Analysis and Development Framework, in Policy Studies Journal, vol. 39, n. 1, p. 16.

BOER, Alexander e VAN ENGERS, Tom. Agile: a problem-based model of regulatory policy making. In: Artificial Intelligence and Law, vol. 21, 2013, p. 399-423.

BORDIGNON, Genuíno; QUEIROZ, Arlindo; e GOMES, Lêda. O Planejamento Educacional no Brasil. Brasília: Fórum Nacional de Educação, 2011.

BOVENS, Mark, e 't HART, Paul. Revisiting the Study of Policy Failures, in Journal of European Public Policy, p. 1-13, 2016.

BRADY, Henry E., e COLLIER, David (eds.). Rethinking Social Inquiry. Diverse Tools, Shared Standards. Lanham/Boulder/New York/Toronto/Oxford: Rowman \& Littlefield, 2004.

BRASIL. Fórum Nacional de Educação. O Planejamento Educacional no Brasil. Disponível em: http://pne.mec.gov.br/images/pdf/pne conhecendo 20 metas.pdf 
BRASIL. Instituto Brasileiro de Geografia e Estatística. Pesquisa Nacional por Amostra de Domicílios 2015. Disponível em http://ibge.gov.br/home/estatistica/pesquisas/pesquisa resultados.php?id pesquisa= $\underline{40}$

BRASIL. Ministério da Educação, Fundação Joaquim Nabuco. Manifesto dos Pioneiros da Educação Nova (1932) e dos Educadores (1959). Recife: Editora Massangana, 2010.

BRASIL. Ministério da Educação, Secretaria de Articulação com os Sistemas de Ensino do Ministério da Educação. Planejando a Próxima Década - Conhecendo as 20 Metas do Plano Nacional de Educação. Brasília: MEC, 2014a.

BRASIL. Ministério do Planejamento, Orçamento e Gestão. Secretaria de Planejamento e Investimentos Estratégicos. O Desafio do Planejamento Governamental. Brasília: Ministério do Planejamento, Orçamento e Gestão, 2002.

BRASIL. Tribunal de Contas da União. Dez passos para a boa governança. Brasília: TCU, Secretaria de Planejamento, Governança e Gestão, 2014b.

BRAUMOELLER, Bear F., e GOERTZ, Gary. The Methodology of Necessary Conditions, in American Journal of Political Science, v. 44, n.ำ 4, p. 844-858, 2000.

BROWN, George Spencer. Laws of Form. New York: The Julian Press, 1972.

BUCCI, Maria Paula Dallari. Fundamentos para uma Teoria Jurídica das Políticas Públicas. 1a. ed. São Paulo: Saraiva, 2013.

BUCCI, Maria Paula Dallari. Notas para uma metodologia jurídica de análise de políticas públicas. In: Políticas Públicas. Possibilidades e Limites. Belo Horizonte: Fórum, 2008, p. 225-260.

BUCCI, Maria Paula Dallari. O conceito de política pública em direito. In: Políticas Públicas - Reflexões sobre o Conceito Jurídico. São Paulo: Saraiva, 2006, p. 1-50.

BUCCI, Maria Paula Dallari. Quadro de Referência de uma Política Pública. Primeiras Linhas de uma Visão Jurídico-Institucional, texto disponível em http://www.direitodoestado.com.br/colunistas/maria-paula-dallari-bucci/quadro-dereferencia-de-uma-politica-publica-primeiras-linhas-de-uma-visao-juridico-institucional acesso em abril de 2016.

$\mathrm{BUSCH}$, Andreas. The Grundgesetz after 50 Years: Analysing Changes in the German Constitution, in German Politics, v. 9, n. ํ 1, p. 41-60, 2000.

CAIRNEY, Paul e HEIKKILA, Tanya. A Comparison of Theories of the Policy Process, in SABATIER, Paul A. e WEIBLE, Cristopher (eds.). Theories of the Policy Process. Colorado: Westwiew Press, 2014.

CARDOSO JR., José Celso. Planejamento Governamental e Gestão Pública no Brasil: Elementos para Ressignificar o Debate e Capacitar o Estado. Texto para Discussão $1584 \quad-\quad$ IPEA, disponível em http://www.ipea.gov.br/portal/index.php?option=com content\&view=article\&id=9756 
COLLIER, David, e MAHONEY, James. Insights and Pitfalls. Selection Bias in Qualitative Research, in World Politics, v. 49, n.․ 1, p. 56-91, 1996.

COLLINS, Randall. Comparative and Historical Patterns of Education, in HALLINAN, M.T. (ed.), Handbook of the Sociology of Education. New York: Kluwer Academic/Plenum, 2000, p. 213-39.

COSTA, Valeriano Mendes Ferreira. Federalismo e Relações Intergovernamentais: Implicações para a Reforma da Educação no Brasil, in Educação e Sociedade, v. 33, n.. 112, p. 729-748, 2010.

COUTINHO, Diogo. O direito nas políticas públicas. In: Política Pública como Campo Disciplinar. São Paulo: UNESP, 2013.

CRAWFORD, Sue E. S., e OSTROM, Elinor. A Grammar of Institutions, in OSTROM, Elinor (ed.), Understanding Institutional Diversity, p. 137-174. Princeton: Princeton University Press, 2005.

CURY, Carlos R. J. A Desoficialização do Ensino no Brasil: A Reforma Rivadávia, in Educação e Sociedade, v. 30, n. ${ }^{\circ}$ 108, p. 717-738, 2009.

CURY, Carlos R. J. A Qualidade da Educação Brasileira como Direito, in Educação e Sociedade, v. 35, n.․ 129, p. 1053-1066, 2014.

DAMAŠKA, Mirjan R. The Faces of Justice and State Authority. A Comparative Approach to the Legal Process. New Haven \& London: Yale University Press, 1986.

DIMAGGIO, Paul J. e POWELL, Walter W. The Iron Cage Revisited: Institutional Isomorphism and Collective Rationality in Organizational Fields, in American Sociological Review, vol. 48, no. 2, 1983, pp. 147-160.

DIMAGGIO, Paul J. e POWELL, Walter W. (org.). El Nuevo Institucionalismo en el Análisis Organizacional. Ciudad de México: Ed. Fondo de Cultura Económica, 1999.

DINIZ, Josedilton Alves. Eficiência das Transferências Intergovernamentais para a Educação Fundamental de Municípios Brasileiros, 2012, 176 f. Tese (Doutorado em Ciências) - Faculdade de Economia, Administração e Contabilidade da Universidade de São Paulo, São Paulo.

DIXON, Rosalind. Constitutional Amendment Rules: A Comparative Perspective, in Public Law and Legal Theory Working Paper Series n. 347, 2011, texto disponível em http://www.law.uchicago.edu/academics/publiclaw/index.html.

DOURADO, Luiz Fernandes. Sistema Nacional de Educação, Federalismo e os Obstáculos ao Direito à Educação Básica, in Educação e Sociedade, v. 34, n.ำ124, p. 761-785, 2013.

DUARTE, Marisa R. T. e SANTOS, M. Rosimary Soares. Sistema Nacional de Educação e Relações Intergovernamentais no Brasil, in Educação e Sociedade, v. 35, n.․ 129, p. 1115-1136, 2014.

EASTON, David. A Framework for Political Analysis. Englewood Cliffs: Prentice Hall, 1965 a.

EASTON, David. A System Analysis of Political Life. New York. Wiley, 1965 b. 
EASTON, David. The Analysis of Political Structure. New York: Routledge, 1990.

EASTON, David. The Political System. An Inquiry into the State of Political Science. New York: Knopf, 1953.

ELASSY, Noha. The Concepts of Quality, Quality Assurance and Quality Enhancement, in Quality Assurance in Education, v. 23, n.ำ 3, p. 250-261, 2015.

ELLER, Warren e KRUTZ, Glen. Policy Process, Scholarship and the Road Ahead: An Introduction to the 2008 Policy Shootout!, in The Policy Studies Journal, vol. 37, n. $-1,2009$, p. 1-4.

ELKINS, Zachary; GINSBURG, Tom; e MELTON, James. The Endurance of Constitutions. Cambridge: Cambridge University Press, 2009.

ELKINS, Zachary; GINSBURG, Tom; e MELTON, James. The Lifespan of Written Constitutions, USC Faculty Workshop, 2006, disponível em http://www.law.uchicago.edu/alumni/magazine/lifespan, acesso em julho de 2016.

ETIENNE, Julien. Compliance Theory: A Goal Framing Approach, in Law and Policy, v. 33, n. 3 , p. 305-333, 2011.

FEREJOHN, John. The Politics of Imperfection, in Law and Social Inquiry, v. 22, p. 501-31, 1997.

FLÜCKIGER, Alexandre e GUY-ECABERT, Christine (eds.). Guider les parlements et les gouvernements pour mieux légiférer. Les rôles des guides de légistique. Zürich: Schulthess, 2008.

FLÜCKIGER, Alexandre. The Ambiguous Principle of the Clarity of Law, in WAGNER, Anne et al., Obscurity and Clarity in the Law. Aldershot: Ashgate, 2008, p. 9-24.

FLÜCKIGER, Alexandre. Can Better Regulation Be Achieved By Guiding Parliaments and Governments? How the Definition of the Quality of Legislation Affects Law Improvement Methods? In Legisprudence, vol. IV, n.ำ 2, p. 213-218, 2010.

FREITAS, M. C. S. et al. Escola: Lugar de Estudar e de Comer, in Ciência e Saúde Coletiva, v. 18, n.ำ 4, p. 979-985, 2013.

GALTUNG, Johan. Expectations and Interaction Process, in Inquiry, vol. 2, 1959, p. 213-34.

GILBERT, N. e TROITZSCH, K.G. Simulation for the Social Scientist, 2a ed. New York: Open University Press, 2005.

GINSBURG, Tom, e ELKINS, Zachary. Ancillary Powers of Constitutional Courts, in Texas Law Review, v. 87, p. 1431-1461, 2009.

GOERTZ, Gary e LEVY, Jack S. Causal Explanations, Necessary Conditions, and Case Studies: World War I and the End of the Cold War. Londres/New York: Routledge, 2007.

GOMES, Fernando Alves. República e Direito Constitucional - Apontamentos para uma Doutrina do Estado Republicano. 2004, 340 p. Dissertação (Mestrado em Direito) Faculdade de Direito da UFMG, Minas Gerais. 
GOMES, Magno F. Autonomia Privada e Regulação Estatal na Evolução Histórica do Ensino Superior Brasileiro, in Revista da Universidade do Vale do Rio Verde, v. 98, n. ${ }^{-1}$, p. 107-138, 2011.

HABERMAS, Jürgen. Faktizität und Geltung - Beiträge zur Diskurstheorie des Rechts und des demokratischen Rechtstaats. Frankfurt am Main: Suhrkamp, 1992

HALL, Peter A. e TAYLOR, Rosemary C. R. As três versões do neo-institucionalismo. In: Lua Nova, n. 58, 2003, p. 193-223.

HEIDEMANN, Francisco G. e SALM, José Francisco (orgs.). Políticas Públicas. Bases Epistemológicas e Modelos de Análise. 2ª ed., Brasília: Ed. UnB, 2010.

HOFSTAEDTER, Douglas R. Metamagical Themas: Questing for the Essence of Mind and Pattern. New York: Basic Books, 1985

HOOD, Christopher. Explaining Economic Policy Reversals. Buckingham: Open University Press, 1994.

HOWLETT, Michael; RAMESH, M., WU, Xun. Understanding the Persistence of Policy Failures: The Role of Politics, Governance and Uncertainty, in Public Policy Administration, v. 30, n. 3-4, p. 209-220, 2015.

IANNI, Octavio. Estado e Planejamento Econômico no Brasil. 5ª ed. Rio de Janeiro: Civilização Brasileira, 1991.

IMMERGUT, Ellen. O núcleo teórico do novo institucionalismo. In Políticas Públicas. Coletânea. (Enrique Saravia e Elisabete Ferrarezi, orgs.), vol. 1. Brasília: ENAP, 2006, pp. 155-195

IMMERGUT, Ellen. The Rules of the Game: The Logic of Health Policy-Making in France, Switzerland and Sweden, in Fischer, Frank., Miller, Gerald J., e Sidney, Mara S. (eds.), Handbook of public policy analysis: theory, politics, and methods. Boca Raton: CRC Press, 2007, p. 57 e ss.

INSTITUTO PAULO MONTENEGRO e AÇÃO EDUCATIVA. Indicador de Alfabetismo Funcional 2015- Alfabetismo no Mundo do Trabalho, disponível em http://www.ipm.org.br/pt-br/programas/inaf/relatoriosinafbrasil/Paginas/default.aspx

JACOB CHAVES, Vera L. Política de Financiamento e a Expansão da Educação Superior no Brasil: o Público e o Privado em Questão, in Educação Temática Digital, v. 17, n. $\stackrel{\circ}{2}$, p. 427-441, 2015.

JACKSON, Jonathan e TYLER, Tom R. Popular legitimacy and the exercise of legal authority: motivating compliance, cooperation and engagement. In: Psychology, Public Policy and Law, vol. 20, no. 1, 2014, p. 78-95.

JOHN, Peter. The Three Ages of Public Policy: Theories of Policy Change and Variation Reconsidered, Paper prepared for the panel "The political science of public policy", held at the American Political Science Association meeting' San Francisco, 36 September 2015, disponível em https://papers.ssrn.com/sol3/papers.cfm?abstract id=2286711, acesso em agosto de 2016. 
KARPEN, Ulrich. Zum gegenwartigen Stand der Gesetzgebungslehre in der Bundesrepublik Deutschland, in Zeitschrift für Gesetzgebung, no 01, 1986, p. 5-32.

KARPEN, Ulrich. Good Governance Through Transparent Application of the Rule of Law, in European Journal of Law Reform, v. 11, n. 2, p. 213-223, 2009.

KIESERLING, André. Kommunikation unter Anweseuden: Studien über Interaktionssysteme. Frankfurt am Main: Suhrkamp, 1999.

KING, Gary; KEOHANE, Robert O.; e VERBA, Sidney. Designing Social Inquiry: Scientific Inference in Qualitative Research. Princeton: Princeton University Press, 1994.

KING, Gary; KEOHANE, Robert O.; e VERBA, Sidney. The importance of research design, in BRADY, Henry E., e COLLIER, David (eds.) Rethinking Social Inquiry. Diverse Tools, Shared Standards. Lanham/Boulder/New York/Toronto/Oxford: Rowman \& Littlefield, 2004, p. 181-191.

KLEIN, Julie T. Prospects for Transdisciplinarity, in Futures, v. 36, p. 515-526, 2004.

KREIS, Anthony M. E CHRISTENSEN, Robert K. Law and Public Policy, in The Policy Studies Journal, v. 41, n.ำ S1, p. 38-52, 2013.

CALAZANS, M. J.; GARCIA, W.; KUENZER, A. Planejamento e Educação no Brasil, 6ª ed. São Paulo: Cortez, 2003.

LAFER, Celso. O Planejamento no Brasil: observações sobre o Plano de Metas (1956-1961). In: LAFER, Bety Mindlin (org.). Planejamento no Brasil. $3^{\text {a }}$ ed. São Paulo: Editora Perspectiva, 1975.

LASCOUMES, Pierre e LE GALÈS, Patrick (eds.). Gouverner par les Instruments. Paris: Presses de Sciences Po, 2004.

LASSIBILLE, Gérard. International Assessment Surveys of Education Achievement in Developing Countries: Why Education Economists Should Care, in Comparative Economic Studies, v. 57, p. 655-668, 2015.

LASSWELL, Harold D. The Policy Orientation, in LERNER, Daniel e LASSWELL, H. D. (org.). The Policy Sciences: Recent Developments in Scope and Method. Stanford: Stanford University Press, 1951, p. 3-15.

LAWRENCE, Paul R. e LORSCH, Jay W. O Desenvolvimento de Organizações: Diagnóstico e Ação. São Paulo: Editora Edgar Blücher, 1972.

LIJPHARDT, Arend. Patterns of Democracy: Government Forms and Performance in Thirty-Six Democracies. New Haven: Yale University Press, 1999.

LOCKE, John. Some Thoughts Concerning Education. New York: P.F. Collier \& Son, 1909-1914 (1693), disponível em http://www.bartleby.com/37/1/

LOEVINGER, Lee. Jurimetris. The Next Step Forward, in Minnesota Law Review, vol. 33, ํㅡ 5, 1949.

LOEVINGER, Lee. Jurimetris: Science and Prediction in the Field of Law, in Minnesota Law Review, vol. 46, 1961-62. 
LORENZ, Astrid. How to measure constitutional rigidity: four concepts and two alternatives, in Journal of Theoretical Politics, v. 17, p. 339-361, 2005.

LOSANO, Mario G. Sistema e Estrutura no Direito - vol. 3, Do Século XX à PósModernidade. São Paulo: WMF Martins Fontes, 2011.

LÜBBE, Hermann. Die Modernität in der Industriegesellschaft - und danach?, in Bergedorfer Gespräche, n.ㅇ 82, 1987, p. 9-17.

LUHMANN, Niklas. Öffentlich- rechtliche Entschädigung, rechtspolitisch betrachtet. Berlin: Duncker \& Humblot, 1965.

LUHMANN, Niklas. Le norme nella prospettiva sociologica, in GIASANTI, A. e POCAR, V. (eds .), La teoría funzionale del diritto. Milano: Unicopli, 1981, p. 51-83.

LUHMANN, Niklas. Insistence on Systems Theory: Perspectives from Germany - An Essay, in Social Forces, v. 61, n.ำ 4, 1983.

LUHMANN, Niklas. Sociologia do Direito, vols. I e II. Rio de Janeiro: Edições Tempo Brasileiro, 1985.

LUHMANN, Niklas. The Theory of Social Systems and Its Epistemology: Reply to Danilo Zolo's Critical Comments, in Philosophy of the Social Sciences, vol. 16, n.. 1, 1986.

LUHMANN, Niklas. Law as a Social System, in Northwestern University Law Review, vol. 83, 1989.

LUHMANN, Niklas. La Differenziazione del Diritto. Bologna: II Mulino, 1990a.

LUHMANN, Niklas. Political Theory in the Welfare State, trad. e introd. de John Bednarz, Jr. Berlin/New York: Walter de Gruyter, 1990b.

LUHMANN, Niklas. Sistemi Sociali - Fondamenti di una Teoria Generale. Bologna: II Mulino, 1990c.

LUHMANN, Niklas. Verfassung als evolutionäre Errungenschaft, in Rechtshistoriches Journal, n. 9 9, p. 176-220,1990d.

LUHMANN, Niklas. Operation Closure and Structural Coupling: The Differentiation of the Legal System, in Cardozo Law Review, vol. 13, 1992.

LUHMANN, Niklas e DE GIORGI, Raffaele. Teoria della società, 5a ed. Milano: Franco Angeli, 1993.

LUHMANN, Niklas. Die Wirtschaft der Gesellschaft. Frankfurt am Main: Suhrkamp, 1994.

LUHMANN, Niklas. Das Recht der Gesellschaft. Frankfurt am Main: Suhrkamp, 1995a.

LUHMANN, Niklas. Kausalität im Süden, in Soziale Systeme. Zeitschrift für soziologische Theorie, v. 1, p. 7-28, 1995b.

LUHMANN, Niklas. Soziologische Aufklärung, Bd. 6, Die Soziologie und der Mensch. Opladen: Westdeutscher Verlag, 1995c. 
LUHMANN, Niklas. Organización y Decisión. Autopoiesis, Acción y Entendimiento Comunicativo, introdução de Darío Rodríguez Mansilla. México, DF: Anthropos Editorial, 1997a.

LUHMANN, Niklas. Die Gesellschaft der Gesellschaft, vol. 1 e 2. Frankfurt am Main: Suhrkamp, 1997b.

LUHMANN, Niklas. Complejidad y Modernidad: De la Unidad a la Diferencia. Madrid: Editorial Trotta, 1998.

LUHMANN, Niklas. A Improbabilidade da Comunicação, $2^{a}$ ed. Lisboa: Vega, 1999a.

LUHMANN, Niklas. Zweckbegriff und Systemrationalität. Frankfurt am Main: Suhrkamp, 1999b.

LUHMANN, Niklas. Das Erziehungssytem der Gesellschaft. Frankfurt am Main: Suhrkamp, 2002a.

LUHMANN, Niklas. Die Politik der Gesellschaft, 2. Auf.. Frankfurt am Main: Suhrkamp, 2002b.

LUHMANN, Niklas. El Derecho de la Sociedad, $2^{\underline{a}}$ ed. Ciudad de México: Editorial Herder/Universidad Iberoamericana, 2005.

LUHMANN, Niklas. Organisation und Entscheidung, $2^{\mathrm{a}}$ ed. Wiesbaden: VS Verlag für Sozialwissenschaften, 2006.

LUHMANN, Niklas. Are There Still Indispensable Norms in Our Society, in Soziale Systeme. Zeitschrift für soziologische Theorie, v. 14, n.ำ 1, p. 18-37, 2008.

LUTZ, Donald S. Toward a Theory of Constitutional Amendment, in The American Political Science Review, v. 88, n.으. 2, p. 355-370, 1994.

MAX-NEEF, Manfred A. Foundations of Transdisciplinarity, in Ecological Economics, v. 53, p. 5-16, 2005.

McCONNEL, Allan. Understanding Policy Success: Rethinking Public Policy. Basingstone: Palgrave-Macmillan, 2010.

McCONNEL, Allan. What is Policy Failure? A Primer to Help Navigate the Maze, in Public Policy Administration, v. 30, n.ํ 3-4, p. 221-242, 2015.

McCOWAN, Tristan. O Crescimento da Educação Superior Privada no Brasil: Implicações para as Questões de Equidade, Qualidade e Benefício Público, in Archivo Analíticos de Políticas Educativas, v. 13, n.ำ 27, p. 1-20, 2005.

MACLURE, Maggie e WALKER, Barbara M. Disenchanted Evenings: the social organisation of talk in parent-teacher consultations in UK secondary schools, in Brithish Journal of Sociology of Education, v. 21, n.․1, p. 5-25, 2000.

MADER, Luzius. L'évaluation législative: pour une analyse empirique des effets de la legislation, in Revue internationale de droit comparé, v. 38, n.ำ. p. 285-286, 1986.

MADER, Luzius. Avaliação prospectiva e análise do impacto legislativo: tornam as leis melhores? In Legislação: Cadernos de Ciência de Legislação, n.ำ 42/43, 2006. 
MAHONEY, James, e GOERTZ, Gary. A Tale of Two Cultures: Contrasting Quantitative and Qualitative Research, in Political Analysis, n.ำ 14, p. 227-249, 2006.

MANGAN, J.A. (ed.) A Significant Social Revolution. Cross-Cultural Aspects of the Evolution of Compulsory Education. London: Woburn, 1994.

MANHEIM, Karl. Liberdade, Poder e Planificação Democrática. São Paulo: Editora Mestre Jou, 1972.

MARQUES, Eduardo. As Políticas Públicas na Ciência Política, in MARQUES, Eduardo e PIMENTA DE FARIA, Carlos Aurélio (orgs.), A Política Pública como Campo Multidisciplinar. São Paulo: Editora Unesp, 2013

MARQUES, Eduardo. O Novo Institucionalismo e os Estudos Legislativos: $A$ Literatura Norte Americana Recente, in Boletim Informativo Bibliográfico, n. 9 37, 1994, p. 3-38.

MATURANA, Humberto e VARELA Francisco. A Árvore do Conhecimento: As Bases Biológicas da Compreensão Humana. São Paulo: Athena, 2001.

MATURANA, Humberto. A Ontologia da Realidade. Belo Horizonte: EDUFMG, 2002.

MATUS, Carlos. Política, Planejamento e Governo. Brasília: IPEA, 1993.

MELO, Osvaldo Ferreira de. Fundamentos da Política Jurídica. Porto Alegre: Sérgio Antonio Fabris, 1994.

MICHELS, Ank. Innovations in democratic governance: how does citizen participation contribute to a better democracy, in International Review of Administrative Sciences, v. 77, n.. 2, p. $275-293,2011$.

MIRABEAU, H.-G. Riqueti, comte de. Travail sur l'Éducation Publique. Paris: Imprimerie Nationale, 1791, disponível em http://gallica.bnf.fr/ark:/12148/bpt6k48974r

MORAND, Charles-Aubert (org.). Légistique formelle et matérielle. Aix-En-Provence: Presses Universitaires d'Aix-Marseille, 1999.

MORAN, Michael. Not Steering but Drowning: Policy Catastrophes and the Regulatory State, in The Political Quarterly, p. 414-427, 2001.

MORRIS, Christopher W. An Essay on the Modern State. Cambridge: Cambridge University Press, 1998.

MYKKÄNEN, Markus e TAMPERE, Kaja. Organizational Decision-Making: The Luhmannian Decision Communication Perspective, in Journal of Business Studies Quarterly, v. 5, n.․ 4, p. 131-146, 2014.

NASCIMENTO, Leonardo Mesquita; COSTA, Ivy Silva; e OLHER, Bruno Silva. Gastos Públicos com Educação: a Análise da Eficiência dos Municípios da Zona da Mata Mineira, in Revista de Ciências da Educação, n. ํ 32, p. 119-143, 2015.

NEGRETTO, Gabriel L. Replacing and Amending Constitutions: The Logic of Constitutional Change in Latin America, in Law and Society Review, v. 46, n.․ 4, p. 749-79, 2012. 
NEVES, Marcelo. Verfassung und Positivität des Rechts in der peripheren Moderne. Eine Theoretische Betrachtung und eine Interpretation des Falls Brasilien. Berlin: Duncker \& Humblot, 1992.

NEVES, Marcelo. A Constitucionalização Simbólica. São Paulo: Martins Fontes, 2007.

NICOLESCU, Basarab. Methodology of Transdisciplinarity - Levels of Reality, Logic of the Included Middle and Complexity,in Transdisciplinary Journal of Engineering \& Science, v. 1, n. 1, p. 19-38, 2010.

NOSENZO, Daniele; OFFERMAN, Theo; SEFTON, Martin; e VAN DER VEEN, Aiko. Encouraging Compliance: Bonuses Versus Fines in Inspection Games, in The Journal of Law, Economics and Organization, v. 30, n.ำ 3, p. 623-648, 2013.

NUNES, Marcelo Gedes. Jurimetria. Como a Estatística pode Reinventar o Direito. São Paulo: RT, 2016.

OLIVEIRA, Romualdo P. A Transformação da Educação em Mercadoria no Brasil, in Educação e Sociedade, v. 30, n. ํ 108, p. 739-760, 2009.

ORGANIZATION FOR ECONOMIC COOPERATION AND DEVELOPMENT. Programme for International Student Assessment - PISA 2015, Paris: OECD Publishing, 2016, disponível em: http://www.oecd.org/pisa/publications/

ORGANIZATION FOR ECONOMIC COOPERATION AND DEVELOPMENT. LowPerforming Students: Why They Fall Behind and How To Help Them Succeed. Paris: OECD Publishing, 2016, disponível em: http://www.keepeek.com/Digital-AssetManagement/oecd/education/low-performing-students 9789264250246en\#.WFB5CfmU2t8

OSBORNE, D., e GAEBLER, T. Reinventing Government: How the Entrepreneurial Spirit is Transforming the Public Sector. Reading: Addison-Wesley, 1992.

OSTROM, Elinor. Governing the Commons: The Evolution of Institutions for Political Action. New York: Cambridge University Press, 1990.

OSTROM, Elinor. Institutional Rational Choice. An Assessment of the Institutional Analysis and Development Framework. In: SABATIER, Paul A. (ed.), Theories of the Policy Process. Colorado: Westwiew Press, 2007.

OSTROM, Elinor. Understanding Institutional Diversity. Princeton: Princeton Universtiy Press, 2005.

OSTROM, Elinor; GARDNER, Roy; e WALKER, James. Rules, Games and Common-Pool Resources. Ann Arbor: University of Michigan Press, 1994.

PARSONS, Talcott e SHILS, Edward. Toward a General Theory of Action. Cambridge: Harvard University Press, 1951.

PARSONS, Talcott. On building social system theory: a personal history. In: Daedalus. Journal of the American Academy of Arts and Science, 1970, p. 826-881.

PARSONS, Talcott. Societies. Evolutionary and Comparative Perspectives. Englewood Cliffs: Prentice Hall, 1966. 
PARSONS, Talcott. The present position and prospects of systematic theory. In: Twentieth Century Sociology. New York: The Philosophical Library, 1945.

PARSONS, Wayne. Not Just Steering, But Weaving: Relevant Knowledge and the Craft of Building Policy Capacity and Coherence, in Australian Journal of Public Administration, v. 63, n.' ${ }^{\circ}$ 1, p. 43-57, 2004.

PEARSON / ECONOMIST INTELLIGENCE UNIT. The Learning Curve Index 2014, disponível em http://thelearningcurve.pearson.com/index/index-ranking.

PETERS, B. Guy. State Failure, Governance Failure and Policy Failure: Exploring the Linkages, in Public Policy Administration, v. 30, n. - 3-4, p. 261-276, 2015.

PETRIDOU, Evangelia. Theories of the Policy Process: Contemporary Scholarship and Future Directions, in Policy Studies Journal, v. 42, n.. S1, p. 12-32, 2014.

PINTO, Élida Graziane. Financiamento dos Direitos à Saúde e à Educação - Uma Perspectiva Constitucional. Belo Horizonte: Editora Fórum, 2015.

PIRES, Daniela de O. O Histórico da Relação Público-Privado no Brasil na Promoção do Direito à Educação, in E-hum, v. 5, n.․․ 2, p. 153-171, 2012.

RAMOS, M. D., e OLIVEIRA DRI, W. I. O Setor Privado no Sistema Educacional Brasileiro: Uma Vertente da Mercantilização da Educação, in Acta Scientiarum Education, v. 34, n.․․ 1, p. 71-80, 2012.

RASCH, Bjørn E. Foundations of Constitutional Stability: Veto Points, Qualified Majorities, and Agenda-Setting Rules in Amendment Procedures, 2008.

RASCH, Bjørn E., e CONGLETON, Roger D. Amendment Procedures and Constitutional Stability, p. 536-561, 2006, disponível em http://rdc1.net/forthcoming/DCD\%20(Chap\%2012,\%20Amendment\%20Procedures,\% 20Congleton\%20and\%20Rausch).pdf

REALE, Miguel. Teoria do Direito e do Estado. São Paulo: Saraiva, 2000.

REGO, José Márcio; MARQUES, Rosa Maria (Orgs.). Economia brasileira. 3. ed. São Paulo: Saraiva, 2003.

RENARD, Didier; CAILLOSSE, Jacques; e BÉCHILLON, Denys de (org.). L'Analyse de Politiques Publiques aux Prises avec le Droit. Paris: LGDJ, 2000.

RIPLEY, Randall B. Stages of the Policy Process, in MCCOOL, Daniel C. (ed.). Public Policy Theories, Models, and Concepts. New Jersey: Prentice Hall, 1995, p. 157 e ss.

ROBERTS, Andrew. The Politics of Constitutional Amendment in Postcommunist Europe, in Constitution and Political Economy, v. 20, p. 99-117, 2009.

ROBSON, W. A. Welfare State and Welfare Society. London: Allen \& Unwin, 1976.

ROEHL, Tobias. What PISA Measures: Some Remarks on Standardized Assessment and Science Education, in Cultural Studies of Science Education, v. 10, n.. 4, p. 1215-1222, 2015. 
ROZNAI, Yaniv. The Theory and Practice of "Supra-Constitutional" Limits on Constitutional Amendments, in International and Comparative Law Quarterly, v. 62,

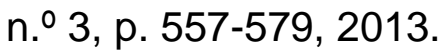

ROZNAI, Yaniv. Unconstitutional Constitutional Amendments: A Study of the Nature and Limits of Constitutional Amendment Powers. Tese (doutorado em filosofia), 363 p., Londres, Department of Law of the London School of Economics, 2014.

ROZNAI, Yaniv. Unamendability and the Genetic Code of the Constitution, in Public Law and Legal Theory Research Paper Series, Working Paper n. 15-13, 2015.

RUANO DE LA FUENTE, José Manuel. Contra la participación: discurso y realidad de las experiencias de participación ciuidadana, in Política y Sociedad, v. 47, n.ำ 3, p. 93-108, 2010.

SABATIER, Paul A. (ed.). Theories of the Policy Process. Colorado: Westwiew Press, 2007.

SABATIER, Paul A. e WEIBLE, Cristopher (eds.). Theories of the Policy Process. Colorado: Westwiew Press, 2014.

SANTOS, Eugênio Andrade Vilela dos. O Confronto entre o Planejamento Governamental e o PPA. In: A Reinvenção do Planejamento Governamental no Brasil, disponível em http://www.ipea.gov.br/agencia/images/stories/PDFs/livros/livros/livro dialogosdesen vol04.pdf

SAVIANI, Demerval. Desafios da Construção de um Sistema Nacional Articulado de Educação, in Trabalho, Educação e Saúde, v. 6, n.ํ 2, p. 213-231, 2008.

SAVIANI, Demerval. Sistema Nacional de Educação Articulado ao Plano Nacional de Educação, in Revista Brasileira de Educação, v. 15, n. 44, p. 380-412, 2010.

SCHARPF, Fritz W. Games Real Actors Play. Actor-Centered Institutionalism in Policy Research. Boulder: Westview Press, 1997.

SCHERER, Sabrina; WIMMER, Maria A.; e MARKISIC, Suvad. Bridging narrative scenario texts and formal policy modeling through conceptual policy modeling. In: Artificial Intelligence and Law, vol. 21, 2013, p. 455-484.

SCHLAGER, Edella e WEIBLE, Christopher. New Theories of the Policy Process, in The Policy Studies Journal, vol. 41, n. 3, 2013, p. 389-396.

SEIDL, David, e BECKER, Kai Helge (eds.). Luhmann and Organization Studies. Copenhagen/Malmö: Liber \& Copenhagen Business Press, 2006a.

SEIDL, David, e BECKER, Kai Helge. Organization as Distinction Generating and Processing Systems: Niklas Luhmann's Contribution to Organization Studies, in Organization, vol. 13, n.․ 1, p. 9-35, $2006 \mathrm{~b}$.

SHAPIRO, Sidney, e MURPHY, Richard. Public Participation Without a Public: The Challenge for Administrative Policymaking, in Missouri Law Review, v. 78, p. 489510, 2013. 
SHEPSLE, Kenneth A. Studying Institutions: Some Lessons from the Rational Choice Approach, in Journal of Theoretical Politics, v. 1, n. 2, p. 131-147.

SILVA, Cleiton Martins Duarte da. Eficiência na Alocação de Recursos Públicos na Educação Básica em Minas Gerais. 2013, 185 f. Dissertação (Mestrado em Administração). Universidade Federal de Lavras, Minas Gerais.

SILVA, Ítalo Batista da e SILVA, Ed Francklin da. Aspectos Históricos dos Planos Nacionais de Educação no Brasil: da Década de 30 à Década de 80, in Holos, ano 22, 2006.

SIMON, Herbert A. Modelo Comportamental de Decisão Racional, in HEIDEMANN, Francisco G. e SALM, José Francisco (orgs.). Políticas Públicas. Bases Epistemológicas e Modelos de Análise. 2ª ed., Brasília: Ed. UnB, 2010.

SMART, J; SCOTT, M; MCCARTHY, J.B.; TAN, K.T.; ARGYRAKIS, P.; BISHOP, S.; CONTE, R. ; HAVLIN, S.; SAN MIGUEL, M.; e STAUFFACHER, D. Big Science and Big Administration - Confronting the Governance, Financial, and Legal Challenges for FuturlCT, in The European Physical Journal Special Topics, v. 214, 2012, p. 635-666.

SMELSER, Neil. The Contest between Family and Schooling in Nineteenth-Century Britain, in ALEXANDER, J. C., e COLOMY, P. (eds.), Differentiation Theory and Social Change, New York: Columbia University Press, 1990.

SOUZA, Celina. Regras e Contexto: As Reformas da Constituição de 1988, in DADOS - Revista de Ciências Sociais, v. 51, n.․ 4, p. 791-823, 2008.

STEPHANI, Heinrich. Grundriß der Staatserziehungswissenschaft. Weißenfels/Leipzig: Friedrich Severin, 1797. Disponível em http://reader.digitalesammlungen.de/de/fs1/object/display/bsb11108601 00005.html

SUBER, Peter. The Paradox of Self-Amendment: A Study of Law, Logic, Omnipotence, and Change. Bern: Peter Lang International Academic Publishers, 1990.

SUCHMAN, Mark C. On beyond Interest: Rational, Normative and Cognitive Perspectives in the Social Scientific Study of Law, in Wisconsin Law Review, p. 475501, 1997.

TEIXEIRA, Ana C. C., e SILVA, Carla A. Participação Social e Democratização do Estado, in Política \& Sociedade, n.ำ 5, p. 249-254, 2004.

THYGESEN, Niels Thyge. Steering Technologies as Observation, in Cybernetics and Human Knowing, v. 14, n.ำ 2-3, p. 151-172, 2007.

TRAINA-CHACON, José-Marcelo, e CALDERÓN, Adolfo-Ignácio. A Expansão da Educação Superior Privada no Brasil: do Governo FHC ao Governo Lula, in Revista Iberoamericana de Educación Superior, n. 17, v. IV, p. 78-100, 2015.

TSEBELIS, George. The Time Inconsistency of Long Constitutions: Evidence from the World, artigo apresentado no Quality of Government Institute da Universidade de Gothenburg, e no Kellogg Institute, de Notre Dame, 2015. 
TSEBELIS, George, e NARDI, Dominic J. A Long Constitution is a (Positively) Bad Constitution. Evidence from OECD Countries, in British Journal of Political Science, v.

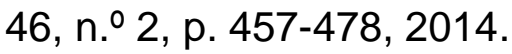

TYLER, Tom R. e JACKSON, Jonathan. Popular Legitimacy and the Exercise of Legal Authority: Motivating Compliance, Cooperation, and Engagement, in Psychology, Public Policy and Law, v. 20, n. 1, p. 78-95, 2014.

VAN ASSCHE, Kristof e VERSCHRAEGEN, Gert. The Limits of Planning: Niklas Luhmann's Systems Theory and the Analysis of Planning and Planning Ambitions, in Planning Theory, v. 7, n.. 3, p. 263-283, 2008.

VAN ASSCHE, Kristof; BEUNEN, Raoul; SMIT, Anneke; e VERSCHRAEGEN, Gert. Planning and Law in Evolving Governance, in Evolutionary Governance Theory. Theory and Applications. Heidelberg/New York/Dordrecht/London: Springer International Publishing, 2015.

VANDERSTRAETEN, Raf. The Autopoiesis of Educational Organizations: The Impact of Organizational Setting on Educational Interaction, in Systems Research and Behavioral Science, n. 19, p. 243-253, 2002.

VANDERSTRAETEN, Raf. An Observation of Luhmann's Observation of Education, in European Journal of Social Theory, vol. 6, n. 1, p. 133-143, 2003.

VANDERSTRAETEN, Raf. The Social Differentiation of the Educational System, in Sociology, v. 38, n. -2 , p. 255-272, 2004a.

VANDERSTRAETEN, Raf. Emerging Mechanisms of Educational Interaction, in Educational Review, v. 56, n. 1 1, p. 43-52, 2004b.

VANDERSTRAETEN, Raf. The Historical Triangulation of Education, Politics and Economy, in Sociology, v. 40, n.. 1, p. 125-142, 2006.

VANDERSTRAETEN, Raf, e BIESTA, Gert. How is Education Possible? Pragmatism, Communication and the Social Organisation of Education, in British Journal of Educational Studies, v. 54, n.. 2, p. 160-174, 2006.

VICK, Douglas W. Interdisciplinarity and the Discipline of Law, in Journal of Law and Society, v. 31, no 2, p. 163-193, 2004.

VICKERS, G. Values, Norms and Policies, in Policy Science, no. 4, p. 103-111, 1973.

VIEIRA, Sofia Lerche. A Educação nas Constituições Brasileiras: Texto e Contexto, in Revista Brasileira de Estudos em Pedagogia, vol. 88, n.․ 219, 2007, p. 291-309.

VIEIRA, Oscar V. et al. Resiliência Constitucional. Compromisso Maximizador, Consensualismo Político e Desenvolvimento Gradual. São Paulo: Direito GV, 2013.

WALLIS, Steven e WRIGHT, Bernadette. Integrative Propositional Analysis: The missing Link for Creating More Effective Laws, in Annual Science of Laws Conference, San Diego, California, Novembro de 2015. 
WHITTEMORE, Andrew H. Practitioners Theorize, Too: Reaffirming Planning Theory in a Survey of Practitioner's Theories, in Journal of Planning Education and Research, v. 35, n. 1, p. 76-85, 2015.

WILLKE, Helmut. Systemtheorie entwickelter Gesselschaftyen: Dynamic und Riskanz moderner gesselschatliche Selbstorganization. München: Weinheim, 1989.

WINTGENS, Luc. Legisprudence as a New Theory of Legislation, in Ratio Juris, vol. 19, n. 1, p. 1-25, 2006.

YEE, Wai-Hang; TANG, Shui-Yan; e LO, Carlos Wing-Hung. Regulatory Compliance when the Rule of Law is Weak; Evidence from China's Environmental Reform, in Journal of Public Administration Research and Theory, v. 16, n. 1, p. 95-112, 2016. 


\section{ANEXO: ANÁLISE DESCRITIVA DAS METAS DO PNE 2014.}

Vejamos, abaixo, uma análise possível das metas do PNE 2014, organizada segundo as cinco categorias apontadas no cap. 5.2.1, item II. Como estruturas de programas finalísticos, essas metas podem servir como marcadores e indutores da ação política do Estado, simbolicamente dignificados pela inserção em lei, mas não como gatilhos de efeitos condicionados. Esta análise, assim, serve exclusivamente ao propósito de visualizar tais estruturas, no que elas apontam para um estado desejável de coisas, para um futuro presente, que se quer fazer coincidir o máximo possível com o presente futuro.

\section{- metas de garantia do diReito à educAÇÃo básica com QUALIDADE.}

Meta 1: universalizar, até 2016, a educação infantil na pré-escola para as crianças de 4 (quatro) a 5 (cinco) anos de idade e ampliar a oferta de educação infantil em creches de forma a atender, no mínimo, $50 \%$ (cinquenta por cento) das crianças de até 3 (três) anos até o final da vigência deste PNE.

\begin{tabular}{|c|c|c|c|c|}
\hline $\begin{array}{l}\text { Núcleo(s) da } \\
\text { ação }\end{array}$ & Objeto & Público-alvo & Índices/objetivos & Prazos \\
\hline $\begin{array}{l}\text { Universalizar; } \\
\text { ampliar; atender. }\end{array}$ & $\begin{array}{l}\text { A educação } \\
\text { infantil na pré- } \\
\text { escola; a oferta de } \\
\text { educação infantil } \\
\text { em creches. }\end{array}$ & $\begin{array}{l}\text { Crianças de } 4 \text { a } 5 \\
\text { anos de idade; } \\
\text { crianças de até } 3 \\
\text { (três) anos. }\end{array}$ & $\begin{array}{l}100 \% \text { para a pré- } \\
\text { escola } \\
\text { (universalização); } \\
\text { mínimo de } 50 \% \\
\text { (cinquenta por } \\
\text { cento) do público } \\
\text { alvo para } \\
\text { educação infantil. }\end{array}$ & $\begin{array}{l}\text { Até 2016; até o } \\
\text { final da vigência } \\
\text { deste PNE. }\end{array}$ \\
\hline
\end{tabular}

Meta 2: universalizar o ensino fundamental de 9 (nove) anos para toda a população de 6 (seis) a 14 (quatorze) anos e garantir que pelo menos 95\% (noventa e cinco por 
cento) dos alunos concluam essa etapa na idade recomendada, até o último ano de vigência deste PNE.

\begin{tabular}{|l|l|l|l|l|}
\hline $\begin{array}{l}\text { Núcleo(s) da } \\
\text { ação }\end{array}$ & Objeto & Público-alvo & Índices/objetivos & Prazos \\
\hline $\begin{array}{l}\text { Universalizar, } \\
\text { garantir. }\end{array}$ & $\begin{array}{l}\text { Ensino } \\
\text { fundamental } \\
\text { duração de } \\
\text { (nove) anos. }\end{array}$ & $\begin{array}{l}\text { Toda a população } \\
\text { de 6 (seis) a 14 } \\
\text { (quatorze) anos. }\end{array}$ & $\begin{array}{l}100 \% \\
\text { (universalização); } \\
\text { pelo menos 95\% } \\
\text { dos atú a último ano } \\
\text { concluindo essa } \\
\text { etapa na idade } \\
\text { recomendada. }\end{array}$ & $\begin{array}{l}\text { Até } \\
\text { de vigência deste } \\
\text { PNE. }\end{array}$ \\
\hline
\end{tabular}

Meta 3: universalizar, até 2016, o atendimento escolar para toda a população de 15 (quinze) a 17 (dezessete) anos e elevar, até o final do período de vigência deste PNE, a taxa líquida de matrículas no ensino médio para 85\% (oitenta e cinco por cento).

\begin{tabular}{|c|c|c|c|c|}
\hline $\begin{array}{l}\text { Núcleo(s) da } \\
\text { acão }\end{array}$ & Objeto & Público-alvo & İndices/objetivos & Prazos \\
\hline $\begin{array}{l}\text { Universalizar; } \\
\text { elevar. }\end{array}$ & $\begin{array}{lr}\text { Atendimento } & \\
\text { escolar; } & \text { taxa } \\
\text { líquida } & \text { de } \\
\text { matrículas } & \text { no } \\
\text { ensino médio. } & \end{array}$ & $\begin{array}{l}\text { Toda a população } \\
\text { de } 15 \text { (quinze) a } \\
17 \quad \text { (dezessete) } \\
\text { anos. }\end{array}$ & $\begin{array}{l}100 \% \text { de } \\
\text { atendimento } \\
\text { escolar } \\
\text { (universalização); } \\
85 \% \text { de aumento } \\
\text { da taxa líquida de } \\
\text { matrículas. }\end{array}$ & $\begin{array}{l}\text { Até 2016; até o } \\
\text { final do período } \\
\text { de vigência deste } \\
\text { PNE. }\end{array}$ \\
\hline
\end{tabular}

Meta 5: alfabetizar todas as crianças, no máximo, até o final do 30 (terceiro) ano do ensino fundamental.

\begin{tabular}{|l|l|l|l|l|}
\hline $\begin{array}{l}\text { Núcleo(s) da } \\
\text { ação }\end{array}$ & Objeto & Público-alvo & Índices/objetivos & Prazos \\
\hline Alfabetizar. & $\begin{array}{l}\text { A alfabetização, } \\
\text { entendida } \\
\text { conforme certo } \\
\text { critério (não } \\
\text { especificado). }\end{array}$ & $\begin{array}{l}\text { Todas as } \\
\text { crianças. }\end{array}$ & $\begin{array}{l}\text { Alfabetização até } \\
\text { o final do 3o } \\
\text { (terceiro) ano do } \\
\text { ensino a fim do PNE } \\
\text { fundamental. }\end{array}$ & $\begin{array}{l}\text { (art. 30, L. } \\
13.005 / 2014) .\end{array}$ \\
\hline
\end{tabular}


Meta 6: oferecer educação em tempo integral em, no mínimo, 50\% (cinquenta por cento) das escolas públicas, de forma a atender, pelo menos, 25\% (vinte e cinco por cento) dos (as) alunos (as) da educação básica.

\begin{tabular}{|c|c|c|c|c|}
\hline $\begin{array}{l}\text { Núcleo(s) da } \\
\text { ação }\end{array}$ & Objeto & Público-alvo & İndices/objetivos & Prazos \\
\hline Oferecer; atender. & $\begin{array}{l}\text { Educação em } \\
\text { tempo integral. }\end{array}$ & $\begin{array}{l}\text { Alunos de escolas } \\
\text { públicas; alunos } \\
\text { da educação } \\
\text { básica. }\end{array}$ & $\begin{array}{l}50 \% \text { (cinquenta } \\
\text { por cento) das } \\
\text { escolas públicas } \\
\text { funcionando em } \\
\text { tempo integral, } \\
\text { atendendo pelo } \\
\text { menos, } 25 \% \\
\text { (vinte e cinco por } \\
\text { cento) dos (as) } \\
\text { alunos (as) da } \\
\text { educacão básica. }\end{array}$ & $\begin{array}{l}\text { Até o fim do PNE } \\
\begin{array}{ll}\text { (art. 3o, } & \text { L. } \\
13.005 / 2014) .\end{array}\end{array}$ \\
\hline
\end{tabular}

Meta 7: fomentar a qualidade da educação básica em todas as etapas e modalidades, com melhoria do fluxo escolar e da aprendizagem de modo a atingir as seguintes médias nacionais para o ldeb:

\begin{tabular}{|l|l|l|l|l|}
\hline IDEB & 2015 & 2017 & 2019 & 2021 \\
\hline $\begin{array}{l}\text { Anos iniciais do } \\
\text { ensino fundamental }\end{array}$ & 5,2 & 5,5 & 5,7 & 6,0 \\
\hline $\begin{array}{l}\text { Anos finais do ensino } \\
\text { fundamental }\end{array}$ & 4,7 & 5,0 & 5,2 & 5,5 \\
\hline Ensino médio & 4,3 & 4,7 & 5,0 & 5,2 \\
\hline
\end{tabular}

\begin{tabular}{|l|l|l|l|l|}
\hline $\begin{array}{l}\text { Núcleo(s) da } \\
\text { ação }\end{array}$ & Objeto Público-alvo & Índices/objetivos & Prazos \\
\hline $\begin{array}{l}\text { Fomentar; } \\
\text { melhorar; atingir. }\end{array}$ & $\begin{array}{l}\text { Qualidade da } \\
\text { educação básica } \\
\text { em todas as } \\
\text { etapas alunos do ensino } \\
\text { modalidades; } \\
\text { fluxo ensino médio. } \\
\text { aprendizagem. }\end{array}$ & $\begin{array}{l}\text { Atingir as médias } \\
\text { fundamental e do } \\
\text { nacionais para o } \\
\text { ldeb estipuladas } \\
\text { na tabela. }\end{array}$ & $\begin{array}{l}\text { Anos indicados na } \\
\text { tabela. }\end{array}$ & \\
\hline
\end{tabular}


Meta 9: elevar a taxa de alfabetização da população com 15 (quinze) anos ou mais para 93,5\% (noventa e três inteiros e cinco décimos por cento) até 2015 e, até o final da vigência deste PNE, erradicar o analfabetismo absoluto e reduzir em 50\% (cinquenta por cento) a taxa de analfabetismo funcional.

\begin{tabular}{|l|l|l|l|l|}
\hline $\begin{array}{l}\text { Núcleo(s) da } \\
\text { ação }\end{array}$ & Objeto & Público-alvo & Índices/objetivos & Prazos \\
\hline $\begin{array}{l}\text { Elevar; erradicar; } \\
\text { reduzir. }\end{array}$ & $\begin{array}{l}\text { Taxa de } \\
\text { alfabetização; } \\
\text { analfabetismo } \\
\text { absoluto; } \\
\text { analfabetismo } \\
\text { funcional. }\end{array}$ & $\begin{array}{l}\text { Toda a opulação } \\
\text { com 15 (quinze) } \\
\text { anos ou mais. }\end{array}$ & $\begin{array}{l}\text { Taxa de } \\
\text { alfabetização de } \\
93,5 \% \text { dem 2015; } \\
100 \% \text { do } \\
\text { analfabetismo do } \\
\text { absoluto } \\
\text { (erradicação); } \\
50 \% \text { a menos de } \\
\text { analfabetismo } \\
\text { funcional. }\end{array}$ & \\
& & & \\
& & & \\
& & & \\
\end{tabular}

Meta 10: oferecer, no mínimo, 25\% (vinte e cinco por cento) das matrículas de educação de jovens e adultos, nos ensinos fundamental e médio, na forma integrada à educação profissional.

\begin{tabular}{|c|c|c|c|c|}
\hline $\begin{array}{l}\text { Núcleo(s) da } \\
\text { ação }\end{array}$ & Objeto & Público-alvo & İndices/objetivos & Prazos \\
\hline Oferecer. & $\begin{array}{lr}\text { Matrículas } & \text { de } \\
\text { educação } & \text { de } \\
\text { jovens e adultos, } \\
\text { nos ensinos } \\
\text { fundamental e } \\
\text { médio, na forma } \\
\text { integrada a } \\
\text { educação } \\
\text { profissional. }\end{array}$ & $\begin{array}{l}\text { Jovens e adultos } \\
\text { nos ensinos } \\
\text { fundamental e } \\
\text { médio. }\end{array}$ & $\begin{array}{lr}\text { Mínimo 25\% } & \text { das } \\
\text { matrículas } & \text { nos } \\
\text { ensinos } & \\
\text { fundamental } & \text { e } \\
\text { médio. } & \end{array}$ & $\begin{array}{l}\text { 2015; até o fim do } \\
\text { PNE (art. 3o, L. } \\
\text { 13.005/2014). }\end{array}$ \\
\hline
\end{tabular}

Meta 11: triplicar as matrículas da educação profissional técnica de nível médio, assegurando a qualidade da oferta e pelo menos $50 \%$ (cinquenta por cento) da expansão no segmento público.

\begin{tabular}{|l|l|l|l|l|}
\hline $\begin{array}{l}\text { Núcleo(s) da } \\
\text { ação }\end{array}$ & Objeto & Público-alvo & Índices/objetivos & Prazos \\
\hline Triplicar, & Matrículas da & Alunos elegíveis à & $200 \%$ de aumento & Até o fim do PNE \\
\hline
\end{tabular}




\begin{tabular}{|c|c|c|c|c|}
\hline assegurar. & \begin{tabular}{l}
\multicolumn{3}{l}{ educação } \\
profissional \\
técnica de nível \\
médio; qualidade \\
da r oferta; \\
expansão no no \\
seamento público.
\end{tabular} & $\begin{array}{ll}\text { modalidade; } & \\
\text { alunos } & \text { da } \\
\text { educação } & \\
\text { profissional } & \\
\text { técnica de nível } \\
\text { médio. }\end{array}$ & $\begin{array}{lrr}\text { de } & \text { matrículas; } \\
50 \% & \text { (cinquenta } \\
\text { por cento) da } & \text { nor } \\
\text { expansão } & \text { no } \\
\text { segmento público. }\end{array}$ & $\begin{array}{lcl}\text { (art. } & 30 & \text { L. } \\
\text { 13.005/2014). } & \end{array}$ \\
\hline
\end{tabular}

\section{- METAS RELATIVAS À REDUÇÃO dAS DESIGUALdADES E À VALORIZAÇÃO DA DIVERSIDADE}

Meta 4: universalizar, para a população de 4 (quatro) a 17 (dezessete) anos com deficiência, transtornos globais do desenvolvimento e altas habilidades ou superdotação, o acesso à educação básica e ao atendimento educacional especializado, preferencialmente na rede regular de ensino, com a garantia de sistema educacional inclusivo, de salas de recursos multifuncionais, classes, escolas ou serviços especializados, públicos ou conveniados.

\begin{tabular}{|c|c|c|c|c|}
\hline $\begin{array}{l}\text { Núcleo(s) da } \\
\text { ação }\end{array}$ & Objeto & Público-alvo & İndices/objetivos & Prazos \\
\hline $\begin{array}{l}\text { Universalizar; } \\
\text { garantir }\end{array}$ & $\begin{array}{l}\text { Acesso à } \\
\text { educação básica } \\
\text { e ao atendimento } \\
\text { educacional } \\
\text { especializado, } \\
\text { preferencialmente } \\
\text { na rede regular de } \\
\text { ensino; inclusão } \\
\text { educacional; salas } \\
\text { de recursos } \\
\text { multifuncionais; } \\
\text { classes, escolas } \\
\text { ou serviços } \\
\text { especializados. }\end{array}$ & $\begin{array}{l}\text { População de } 4 \\
\text { (quatro) a } 17 \\
\text { (dezessete) anos } \\
\text { com deficiência, } \\
\text { transtornos } \\
\text { globais do } \\
\text { desenvolvimento } \\
\text { e altas } \\
\text { habilidades ou } \\
\text { superdotação. }\end{array}$ & $\begin{array}{l}100 \% \text { do público } \\
\text { alvo } \\
\text { (universalização) }\end{array}$ & $\begin{array}{l}\text { Até o fim do PNE } \\
\text { (art. 30, } \\
\text { 13.005/2014). }\end{array}$ \\
\hline
\end{tabular}

Meta 8: elevar a escolaridade média da população de 18 (dezoito) a 29 (vinte e nove) anos, de modo a alcançar, no mínimo, 12 (doze) anos de estudo no último ano de vigência deste Plano, para as populações do campo, da região de menor escolaridade no país e dos $25 \%$ (vinte e cinco por cento) mais pobres, e igualar a 
escolaridade média entre negros e não negros declarados à Fundação Instituto Brasileiro de Geografia e Estatística - IBGE.

\begin{tabular}{|c|c|c|c|c|}
\hline $\begin{array}{l}\text { Núcleo(s) da } \\
\text { ação }\end{array}$ & Objeto & Público-alvo & Índices/objetivos & Prazos \\
\hline $\begin{array}{l}\text { Elevar; alcançar; } \\
\text { igualar. }\end{array}$ & $\begin{array}{l}\text { Escolaridade } \\
\text { média, definida de } \\
\text { acordo com o } \\
\text { número de anos } \\
\text { de educação } \\
\text { formal. }\end{array}$ & 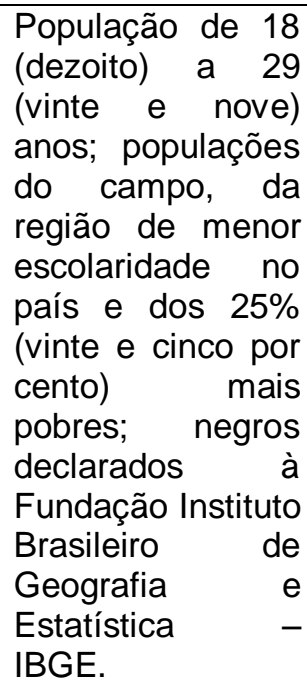 & $\begin{array}{l}\text { Mínimo, } 12 \text { (doze) } \\
\text { anos de estudo. }\end{array}$ & $\begin{array}{l}\text { Último ano } \text { de } \\
\text { vigência } \\
\text { PNE. }\end{array}$ \\
\hline
\end{tabular}

\section{- METAS RELATIVAS À VALORIZAÇÃO dOS PROFISSIONAIS DA EDUCAÇÃO}

Meta 15: garantir, em regime de colaboração entre a União, os Estados, o Distrito Federal e os Municípios, no prazo de 1 (um) ano de vigência deste PNE, política nacional de formação dos profissionais da educação de que tratam os incisos I, II e III do caput do art. 61 da Lei no 9.394, de 20 de dezembro de 1996, assegurado que todos os professores e as professoras da educação básica possuam formação específica de nível superior, obtida em curso de licenciatura na área de conhecimento em que atuam. 


\begin{tabular}{|l|l|l|l|l|}
\hline $\begin{array}{l}\text { Núcleo(s) da } \\
\text { ação }\end{array}$ & Objeto & Público-alvo & Índices/objetivos & Prazos \\
\hline $\begin{array}{l}\text { Garantir; } \\
\text { assegurar. }\end{array}$ & $\begin{array}{l}\text { Política nacional } \\
\text { de formação dos } \\
\text { profissionais da } \\
\text { educação de que } \\
\text { tratam os incisos } \\
\text { I, II e III do caput } \\
\text { do art. 61 da Lei } \\
\text { no 9.394, de 20 } \\
\text { de dezembro de } \\
\text { 1996; formação } \\
\text { específica de } \\
\text { nível superior, } \\
\text { prtida em curso } \\
\text { de licenciatura. }\end{array}$ & & $\begin{array}{l}100 \% \text { do público } \\
\text { educação básica. }\end{array}$ & $\begin{array}{l}\text { Dentro de 1 (um) } \\
\text { ano da vigência } \\
\text { deste } \\
\text { (junho/2015 PNE } \\
\text { vencido). }\end{array}$ \\
\hline
\end{tabular}

Meta 16: formar, em nível de pós-graduação, 50\% (cinquenta por cento) dos professores da educação básica, até o último ano de vigência deste PNE, e garantir a todos (as) os (as) profissionais da educação básica formação continuada em sua área de atuação, considerando as necessidades, demandas e contextualizações dos sistemas de ensino.

\begin{tabular}{|c|c|c|c|c|}
\hline $\begin{array}{l}\text { Núcleo(s) da } \\
\text { ação }\end{array}$ & Objeto & Público-alvo & Índices/objetivos & Prazos \\
\hline $\begin{array}{l}\text { Formar; garantir; } \\
\text { considerar. }\end{array}$ & $\begin{array}{lr}\text { Formação } & \\
\text { continuada; } & \\
\text { necessidades } & \text { e } \\
\text { contextos } & \text { dos } \\
\text { sistemas } & \text { de } \\
\text { ensino. } & \end{array}$ & $\begin{array}{ll}\text { Todos } & \text { os } \\
\text { professores e } & \text { as } \\
\text { professoras da } & \text { da } \\
\text { educação básica. }\end{array}$ & $\begin{array}{l}100 \% \text { do público } \\
\text { alvo. }\end{array}$ & $\begin{array}{l}\text { Até o último ano } \\
\text { de vigência deste } \\
\text { PNE. }\end{array}$ \\
\hline
\end{tabular}

Meta 17: valorizar os (as) profissionais do magistério das redes públicas de educação básica de forma a equiparar seu rendimento médio ao dos (as) demais profissionais com escolaridade equivalente, até o final do sexto ano de vigência deste PNE.

\begin{tabular}{|l|l|l|l|l|}
\hline $\begin{array}{l}\text { Núcleo(s) da } \\
\text { ação }\end{array}$ & Objeto & Público-alvo & Índices/objetivos & Prazos \\
\hline $\begin{array}{l}\text { Valorizar; } \\
\text { equiparar. }\end{array}$ & $\begin{array}{l}\text { Rendimento } \\
\text { médio. }\end{array}$ & $\begin{array}{l}\text { Profissionais do } \\
\text { magistério das } \\
\text { redes públicas de } \\
\text { educação básica. }\end{array}$ & $\begin{array}{l}\text { Atingir o mesmo } \\
\text { nível } \\
\text { remuneração que de o final do } \\
\text { demais } \\
\text { profissionais com }\end{array}$ & $\begin{array}{l}\text { Atex ox ano de } \\
\text { vigência deste } \\
\text { PNE (2020). }\end{array}$ \\
\hline
\end{tabular}




\begin{tabular}{|l|l|l|l|l|}
\hline & & $\begin{array}{l}\text { escolaridade } \\
\text { equivalente. }\end{array}$ & \\
\hline
\end{tabular}

Meta 18: assegurar, no prazo de 2 (dois) anos, a existência de planos de Carreira para os (as) profissionais da educação básica e superior pública de todos os sistemas de ensino e, para o plano de Carreira dos (as) profissionais da educação básica pública, tomar como referência o piso salarial nacional profissional, definido em lei federal, nos termos do inciso VIII do art. 206 da Constituição Federal.

\begin{tabular}{|c|c|c|c|c|}
\hline $\begin{array}{l}\text { Núcleo(s) da } \\
\text { ação }\end{array}$ & Objeto & Público-alvo & Índices/objetivos & Prazos \\
\hline $\begin{array}{l}\text { Assegurar a } \\
\text { existência; tomar } \\
\text { como referência. }\end{array}$ & $\begin{array}{l}\text { Planos de } \\
\text { Carreira para os } \\
\text { (as) profissionais } \\
\text { da educação } \\
\text { básica e superior } \\
\text { pública de todos } \\
\text { os sistemas de } \\
\text { ensino. }\end{array}$ & $\begin{array}{lr}\text { Profissionais } & \text { da } \\
\text { educação básica } \\
\text { e superior pública } \\
\text { de todos os } \\
\text { sistemas } \\
\text { ensino. }\end{array}$ & $\begin{array}{l}\text { Criar planos de } \\
\text { carreira; } \\
\text { assegurar o } \\
\text { pagamento de, no } \\
\text { mínimo, o piso } \\
\text { salarial nacional } \\
\text { para todos os } \\
\text { profissionais da } \\
\text { educação básica } \\
\text { pública. }\end{array}$ & $\begin{array}{l}\text { Dois anos a partir } \\
\text { da entrada em } \\
\text { vigência da Lei } \\
\text { (jun/2016 } \\
\text { vencido). }\end{array}$ \\
\hline
\end{tabular}

\section{- METAS REFERENTES AO ENSINO SUPERIOR}

Meta 12: elevar a taxa bruta de matrícula na educação superior para 50\% (cinquenta por cento) e a taxa líquida para 33\% (trinta e três por cento) da população de 18 (dezoito) a 24 (vinte e quatro) anos, assegurada a qualidade da oferta e expansão para, pelo menos, $40 \%$ (quarenta por cento) das novas matrículas, no segmento público.

\begin{tabular}{|c|c|c|c|c|}
\hline $\begin{array}{l}\text { Núcleo(s) da } \\
\text { ação }\end{array}$ & Objeto & Público-alvo & İndices/objetivos & Prazos \\
\hline $\begin{array}{l}\text { Assegurar a } \\
\text { existência; tomar } \\
\text { como referência. }\end{array}$ & $\begin{array}{lr}\text { Taxas bruta } & \text { e } \\
\text { líquida } & \text { de } \\
\text { matrícula } & \text { na } \\
\text { educação } & \\
\text { superior; } & \\
\text { qualidade } & \text { da } \\
\text { oferta; expansão }\end{array}$ & $\begin{array}{lll}\text { População de } & 18 \\
\text { (dezoito) a } & 24 \\
\text { (vinte e } & \text { quatro) } \\
\text { anos. } & \end{array}$ & $\begin{array}{l}50 \% \text { taxa bruta; } \\
33 \% \text { taxa líquida; } \\
40 \% \text { de expansão } \\
\text { no segmento }\end{array}$ & $\begin{array}{l}\text { Até o fim do PNE } \\
\text { (art. } \quad 30, \\
\text { 13.005/2014). }\end{array}$ \\
\hline
\end{tabular}




\begin{tabular}{|l|l|l|l|l|}
\hline & $\begin{array}{l}\text { das novas } \\
\text { matrículas. }\end{array}$ & púbo. & \\
\hline
\end{tabular}

Meta 13: elevar a qualidade da educação superior e ampliar a proporção de mestres e doutores do corpo docente em efetivo exercício no conjunto do sistema de educação superior para $75 \%$ (setenta e cinco por cento), sendo, do total, no mínimo, $35 \%$ (trinta e cinco por cento) doutores.

\begin{tabular}{|c|c|c|c|c|}
\hline $\begin{array}{l}\text { Núcleo(s) da } \\
\text { ação }\end{array}$ & Objeto & Público-alvo & İndices/objetivos & Prazos \\
\hline Elevar; ampliar. & $\begin{array}{lr}\text { Qualidade } & \text { da } \\
\text { educação } & \\
\text { superior; } & \\
\text { proporção } & \text { de } \\
\text { mestres } & \text { e } \\
\text { doutores do corpo } \\
\text { docente } & \text { em } \\
\text { efetivo exercício } \\
\text { no conjunto do } \\
\text { sistema } & \text { de } \\
\text { educação } & \\
\text { superior. } & \end{array}$ & $\begin{array}{l}\text { Professores } \\
\text { alunos } \\
\text { universitários. }\end{array}$ & $\begin{array}{l}75 \% \text { de mestres e } \\
\text { doutores; } 35 \% \text { de } \\
\text { doutores, do total. }\end{array}$ & $\begin{array}{l}\text { Até o fim do PNE } \\
\text { (art. 30, L. } \\
\text { 13.005/2014). }\end{array}$ \\
\hline
\end{tabular}

Meta 14: elevar gradualmente o número de matrículas na pós-graduação stricto sensu, de modo a atingir a titulação anual de 60.000 (sessenta mil) mestres e 25.000 (vinte e cinco mil) doutores.

\begin{tabular}{|c|c|c|c|c|}
\hline $\begin{array}{l}\text { Núcleo(s) da } \\
\text { ação }\end{array}$ & Objeto & Público-alvo & Índices/objetivos & Prazos \\
\hline Elevar; atingir. & $\begin{array}{l}\text { Número de } \\
\text { matrículas na pós- } \\
\text { graduação stricto } \\
\text { sensu. }\end{array}$ & $\begin{array}{l}\text { Qualquer } \text { um } \\
\text { elegível para um } \\
\text { curso de pós- } \\
\text { graduação strictu } \\
\text { sensu. }\end{array}$ & \begin{tabular}{|l}
\multicolumn{2}{|c|}{ Titulação anual de } \\
60.000 (sessenta \\
mil) mestres e \\
25.000 (vinte e \\
cinco \\
doutores.
\end{tabular} & $\begin{array}{l}\text { Até o fim do PNE } \\
\text { (art. 30, } \\
\text { 13.005/2014). }\end{array}$ \\
\hline
\end{tabular}




\section{- METAS DE GESTÃO DEMOCRÁTICA E DE INVESTIMENTOS PÚBLICOS}

Meta 19: assegurar condições, no prazo de 2 (dois) anos, para a efetivação da gestão democrática da educação, associada a critérios técnicos de mérito e desempenho e à consulta pública à comunidade escolar, no âmbito das escolas públicas, prevendo recursos e apoio técnico da União para tanto.

\begin{tabular}{|c|c|c|c|c|c|}
\hline $\begin{array}{l}\text { Núcleo(s) da } \\
\text { ação }\end{array}$ & Objeto & Público-alvo & & İndices/objetivos & Prazos \\
\hline Assegurar; prever. & $\begin{array}{l}\text { Condições para a } \\
\text { efetivação da } \\
\text { gestão } \\
\text { democrática da } \\
\text { educação, } \\
\text { associada a } \\
\text { critérios técnicos } \\
\text { de mérito e } \\
\text { desempenho e à } \\
\text { consulta pública à } \\
\text { comunidade } \\
\text { escolar, no âmbito } \\
\text { das escolas } \\
\text { públicas. }\end{array}$ & $\begin{array}{l}\text { Todos } \\
\text { envolvidos } \\
\text { sistema } \\
\text { educacional } \\
\text { público. }\end{array}$ & $\begin{array}{l}\text { os } \\
\text { no }\end{array}$ & $\begin{array}{l}\text { Efetividade } \\
\text { (critérios não } \\
\text { especificados); } \\
\text { disponibilização } \\
\text { de recursos. }\end{array}$ & $\begin{array}{l}\text { Dois anos a partir } \\
\text { da publicação da } \\
\text { Lei (jun2016 - } \\
\text { vencido). }\end{array}$ \\
\hline
\end{tabular}

Meta 20: ampliar o investimento público em educação pública de forma a atingir, no mínimo, o patamar de 7\% (sete por cento) do Produto Interno Bruto - PIB do país no $5^{\circ}$ (quinto) ano de vigência desta Lei e, no mínimo, o equivalente a 10\% (dez por cento) do PIB ao final do decênio.

\begin{tabular}{|l|l|l|l|l|}
\hline $\begin{array}{l}\text { Núcleo(s) da } \\
\text { ação }\end{array}$ & Objeto & Público-alvo & Índices/objetivos & Prazos \\
\hline Ampliar; atingir. & $\begin{array}{l}\text { Investimento em } \\
\text { público em pública. } \\
\text { educação púbal. }\end{array}$ & $\begin{array}{l}7 \% \text { do PIB no } \\
\text { quinto ano de } \\
\text { vigência (2019); } \\
10 \% \text { do PIB no } \\
\text { final do decênio } \\
(2024) .\end{array}$ & \\
& & & Global & \\
\hline
\end{tabular}

